\title{
本邦人靑・成年期二於ヶル身體各部 外皮(皮膚)色調
}

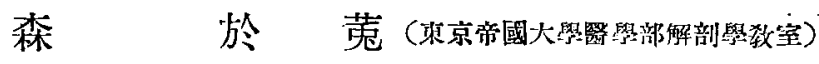 \\ 金子五之助 (日本醫科大學解乵學致室)
}

第1算、緒言

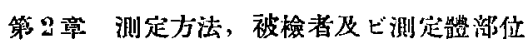

第 3 章 身體各部外皮(皮成)色洞
目次

第 4 章 身體各部外皮(皮解) 色調/分析各含有 量

第 5 章 結果

文噳

\section{第 1 章 緒 言}

外皮(皮膚)色調ノ人類學的見地 $コ$ 重要ナルハ勿論，醫學的方面二亦樞要ナル意義ヨ有スル 八從來發表〉論文二屡不論及セシトコロナリ。

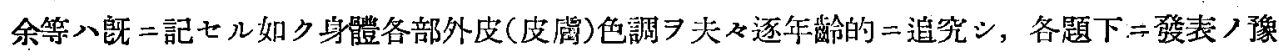

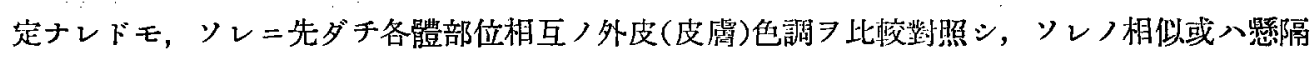

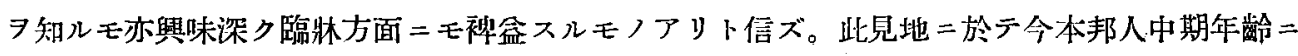
於ケル男子ノモノヨ標準トナシ(女子八單二對照二止メ, 且ツ各年齢=於ケル所見, 其他詳細=

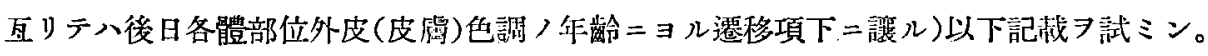

\section{第 2 章 測定方法，被檢者及ビ測定體部位}

測定方法：略ス(森・金子共著：人體皮膚色調测定二就テ，解剖學雜誌第 8 突第 4 號炤和 10 年 7月參照)。

被檢者：男女學生，陸軍兵士，男女工，職噛紹介所ニョレルモ>，其他。

測定體部位 : 頭部(金子著, 邦人顏面皮虞色調 $=$ 就 月參照)

身區幹：前後頸部，胸骨部，乳頭，乳房，上腹部(胎上部)，㓌部，屏肔部，腰背部，肚門周圍 上肢：腋窝, 上膊內外側, 肘, 前膊內外側, 手掌, 手背, 指尖色素。

下肢: 大腿前後面, 膝, 下腿前後面, 內外踝, 足蹠, 足背, 趾尖色素。

\section{第 3 章 身體各部外皮(皮瑭)色調}

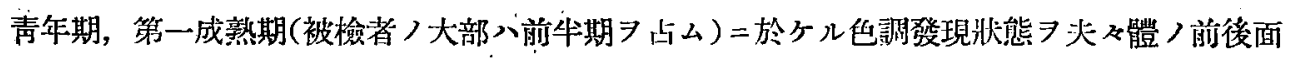
ニ緾メテ表記スレバ次ノ如シ。 
1) 頭部：省格(前記題下參照)ス。

2) 軀幹:

\section{第 1 表. (禹幹前面) 卡段……青籍一期}

\begin{tabular}{|c|c|c|c|c|c|c|c|}
\hline 色 错 & $(\%)^{\text {前 }}$ & 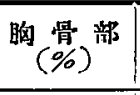 & $(\%)^{\text {頍 }}$ & 腈上部 & 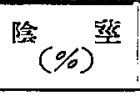 & $(\%)^{\text {荟 }}$ & $\begin{array}{l}\text { 肛周( } \\
\text { 門園 }\end{array}$ \\
\hline $3.0 \mathrm{ec}$ & & & & $2(0.8)$ & & & \\
\hline $\mathrm{fc}$ & & $9(1.5)$ & & $1(0.4)$ & & & \\
\hline fc-gd & & $1(0.8)$ & & & & & \\
\hline fd & & & & $1(0.4)$ & & & \\
\hline$g^{d}$ & $4(2.1)$ & $9(1.5)$ & & $\begin{array}{r}5(1.9) \\
21(9.7) \\
\end{array}$ & & & \\
\hline gd-hd & & & & $3(1.4)$ & & & \\
\hline gd-he & & & & $6(2.8)$ & & & \\
\hline hd & $\begin{array}{l}1(0.5) \\
1(1.9)\end{array}$ & & . & $\begin{array}{r}2(0.8) \\
13(6.0) \\
\end{array}$ & & & \\
\hline kf & $1(0.5)$ & & & & & & \\
\hline $3.25 \mathrm{gd}$ & $1(0.5)$ & . & & & & & \\
\hline 3.5 ec & & $3(0.5)$ & & $\overline{1}(0.4)$ & & & \\
\hline$e c-f d$ & & $1(0.2)$ & & & & & \\
\hline fc-ec & & $1(0.2)$ & & & & & \\
\hline $\mathrm{fc}$ & & $\begin{array}{l}4(1.9) \\
2(0.3)\end{array}$ & & & & & \\
\hline fc-gd & $1(0 . \overline{5})$ & $\begin{array}{l}1(0.5) \\
4(0.7) \\
\end{array}$ & & $1(0.5)$ & & & \\
\hline fd-gd & & $1(0.2)$ & & & & & \\
\hline $\mathrm{gd}$ & $\begin{array}{l}42(22.0) \\
16(34.9)\end{array}$ & $67(31.9)$ & & $\begin{array}{l}49(18.9) \\
23(10.6)\end{array}$ & & & \\
\hline gd-hd & $\begin{array}{l}8(4.2) \\
1(1.9) \\
\end{array}$ & $\begin{array}{l}4(1.9) \\
5(0.8) \\
\end{array}$ & & $\begin{array}{l}4(1.5) \\
5(2.3) \\
\end{array}$ & & & \\
\hline gd-he & & & & $\begin{array}{l}4(1.5) \\
6(2.8)\end{array}$ & & & \\
\hline hd-gd & & $1(0.2)$ & & & | & & \\
\hline hd & $\begin{array}{l}72(37.7) \\
20(38.9) \\
\end{array}$ & $\begin{array}{l}29(13.6) \\
76(12.5)\end{array}$ & & $\begin{array}{l}44(16.9) \\
94(43.3)\end{array}$ & & & \\
\hline hd. ie & $4(2.1)$ & $1(0.5)$ & & $\begin{array}{l}13(5.0) \\
13(6.0)\end{array}$ & & & \\
\hline id & & & & $I(0.4)$ & & & \\
\hline id-ke & & & & $1(0.4)$ & & & \\
\hline ie & $\begin{array}{l}7(3.7) \\
1(1.9)\end{array}$ & $1(0,5)$ & & $\begin{array}{l}61(23.6) \\
28(12.9)\end{array}$ & 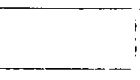 & & \\
\hline ie-kf & & & & $4(1.5)$ & & & \\
\hline
\end{tabular}




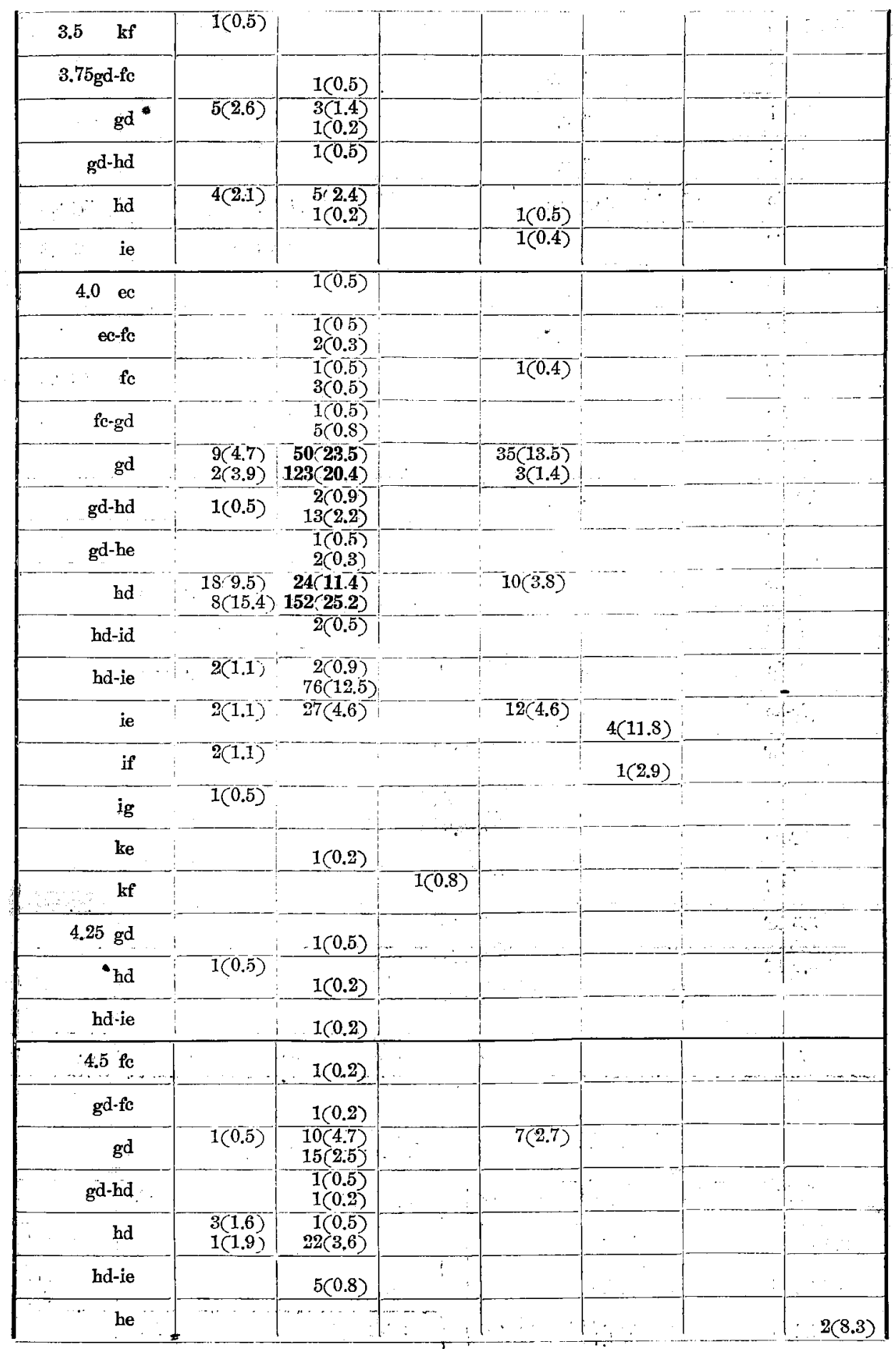




\begin{tabular}{|c|c|c|c|c|c|c|c|}
\hline 4.5 he-ie & & & & & & & $2(8.3)$ \\
\hline id & & $1(0.2)$ & & & & & 8 \\
\hline ie-hd & & $1(0.2)$ & & & & & \\
\hline ie-id & & $1(0.2)$ & & . & & & 3 \\
\hline ie & $1(0.5)$ & $22(3.6)$ & & $\ldots$ & $11(32.4)$ & & $5(20.8)$ \\
\hline if & & & & & $9(26.5)$ & & $2(8.3)$ \\
\hline ke-ie & & $1(0.2)$ & & & & & $\therefore \quad$ \\
\hline $\mathbf{k e}$ & & $1(0.2)$ & & & & & . \\
\hline $\mathrm{kf}$ & & & & & $5(14.7)$ & & $8(33.3)$ \\
\hline $\mathrm{kg}$ & & & & & $4(11.8)$ & & $5(20.8)$ \\
\hline $4.75 \mathrm{kf}$ & & & & & 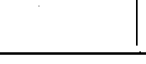 & 3(33.3) & \\
\hline $5.0 \mathrm{gd}$ & & $1(0.2)$ & $1(0.8)$ & & & & i \\
\hline hd & & $4(0.7)$ & $2(1.6)$ & & & & \\
\hline he & & 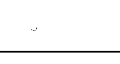 & & & & $2(22,2)$ & \\
\hline ie-id & & $1(0.2)$ & & & & & \\
\hline ie & & $2(0.3)$ & $\begin{array}{r}36(39.5) \\
5(71.4) \\
\end{array}$ & & & $4(44.4)$ & 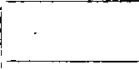 \\
\hline ie-ke & & $1(0.2)$ & & & & & \\
\hline if & & & $10(8.1)$ & & & & \\
\hline kf & & & $\begin{array}{r}44(36.1) \\
2(28.6) \\
\end{array}$ & & & & \\
\hline $\mathrm{kf}-\mathrm{kg}$ & & & $4(3.3)$ & & & & \\
\hline $\mathbf{k g}$ & & & $13(10.7)$ & & & 3 & \\
\hline $5.5 \mathrm{kf}$ & & & $5(4.1)$ & & 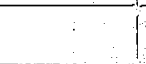 & 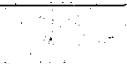 & $0^{\circ}$ \\
\hline $6.0 \mathrm{kf}$ & & & $3(2.5)$ & & & & . \\
\hline $\mathrm{kg}$ & & & $3(2.5)$ & & & & \\
\hline 訫 & $\begin{array}{r}191 \\
52 \\
\end{array}$ & $\begin{array}{l}213 \\
604 \\
\end{array}$ & $\begin{array}{r}122 \\
7 \\
\end{array}$ & $\begin{array}{l}259 \\
217 \\
\end{array}$ & 34 & 9 & 24 \\
\hline
\end{tabular}

苐 2 表 (挋幹後面) 卡段……青第一第成然坦

\begin{tabular}{|c|c|c|c|}
\hline 色調 & 後 $(\%)^{\text {項 }}$ & $\begin{array}{c}\text { 肩惮 } \\
(\%)\end{array}$ & $\begin{array}{c}\text { 喓背 部 } \\
(\%)\end{array}$ \\
\hline $3.0 \mathrm{gd}$ & & $5(1.9)$ & \\
\hline . gd-hd & & $1(0.4)$ & \\
\hline fre ${ }^{\circ}$ d & & $\begin{array}{l}2(0.8) \\
1(1.1)\end{array}$ & $2(1.1)$ \\
\hline
\end{tabular}

\begin{tabular}{|r|r|r|r|}
\hline 3.0 hd-ie & & $1(0.4)$ & \\
\hline $\mathrm{id}$ & & & $1(0.6)$ \\
\hline $\mathrm{ie}$ & & & $\begin{array}{r}1(0.6) \\
1(6.3)\end{array}$ \\
\hline $3.5 \mathrm{fc}-\mathrm{gd}$ & & $\mathrm{t}(1.1)$ & \\
\hline
\end{tabular}




\begin{tabular}{|c|c|c|c|}
\hline $3.5 \mathrm{gd}$ & & $\begin{array}{c}2(0.8) \\
12(13.2)\end{array}$ & \\
\hline gd-hd & & $\begin{array}{l}3(1.2) \\
2(2.2)\end{array}$ & $2(1.1)$ \\
\hline gd-he & & $\begin{array}{c}4(1.6) \\
10(11.0)\end{array}$ & $4(2,2)$ \\
\hline hd & $\begin{array}{l}4(2.5) \\
1(6.3)\end{array}$ & $\begin{array}{r}88(33.9) \\
9(9.9)\end{array}$ & $\begin{array}{r}14(7.8) \\
1(6.3)\end{array}$ \\
\hline hd-id & & & $2(1.1)$ \\
\hline hd-ie & $\begin{array}{l}5(3.1) \\
1(6.3)\end{array}$ & $\begin{array}{l}23(8.7) \\
16(17.6)\end{array}$ & $\begin{array}{r}36(20.0) \\
4(25.0)\end{array}$ \\
\hline he & & . & $1(0.6)$ \\
\hline id & & $\begin{array}{r}1(0.4) \\
10(11.0)\end{array}$ & $10(5.6)$ \\
\hline id-ie & & & $1(6.3)$ \\
\hline id-ke & & & $2(1.1)$ \\
\hline ie-id & & & $5(\mathbf{2 . 8})$ \\
\hline ie & $\begin{array}{r}56(34.2) \\
8(50.0) \\
\end{array}$ & $\mathbf{5 8 ( 2 2 , 3 )}$ & $\begin{array}{r}66(36.7) \\
5(31.3)\end{array}$ \\
\hline ie-ke & & & $1(6.3)$ \\
\hline ie-kf & & $1(1.1)$ & $1(0.6)$ \\
\hline 3.75gd-he & & $\begin{array}{l}1(0.4) \\
1(1.1)\end{array}$ & \\
\hline hd. & & $\begin{array}{l}1(0.4) \\
4(4.4)\end{array}$ & \\
\hline
\end{tabular}

\begin{tabular}{|c|c|c|c|}
\hline 3.75hd-ie & $\begin{array}{l}a \\
4\end{array}$ & $\begin{array}{l}3(1.2) \\
1(1.1)\end{array}$ & $6(3.3)$ \\
\hline id & 77 & $1(0.4)$ & $2(1.1)$ \\
\hline ie & $4(2.5)$ & $\begin{array}{r}19(7.3) \\
6(6.6)\end{array}$ & $\begin{array}{c}14(7.8) \\
2(12.5)\end{array}$ \\
\hline $4.0 \mathrm{gd}$ & $\begin{array}{cc}\cdots & * \\
\cdots & 0\end{array}$ & $3(1.2)$ & \\
\hline gd-hd & & $\begin{array}{l}1(0.4) \\
3(3.3)\end{array}$ & \\
\hline gd-he & & $\begin{array}{l}3(1.2) \\
3(3.3)\end{array}$ & \\
\hline hd & $\begin{array}{l}3(1.9) \\
1(6.3)\end{array}$ & $\begin{array}{l}14(5.4) \\
11(12.1)\end{array}$ & $1(0.6)$ \\
\hline hd-ie & $1(0.6)$ & $7(2.7)$ & $\begin{array}{l}3(1.7) \\
1(6.3)\end{array}$ \\
\hline id & $8(4.0)$ & & \\
\hline ie-id & & & $1(0.6)$ \\
\hline ie & $\begin{array}{r}74(45.4) \\
5(31.3) \\
\end{array}$ & $17(6.5)$ & $6(3.3)$ \\
\hline ie-kf & & & \\
\hline $\mathbf{k f}$ & $2(1.3)$ & & $\because$ \\
\hline $4.5 \mathrm{hd}$ & & $1(0.4)$ & \\
\hline ie & $3(2.5)$ & $1(0.4)$ & \\
\hline 䚵 & $\begin{array}{r}161 \\
16\end{array}$ & $\begin{array}{r}260 \\
91\end{array}$ & $\begin{array}{r}180 \\
16\end{array}$ \\
\hline
\end{tabular}

第 3 表 (上肢内例)

上段……琶华期

下段……策一成染撕

\begin{tabular}{|c|c|c|c|c|c|c|}
\hline 色翮 & ${ }^{\text {腋 }}(\%)^{\text {简 }}$ & $\begin{array}{c}\text { 掖窩前線 } \\
(\%)\end{array}$ & 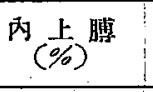 & 內 $(\%)^{\text {肘 }}$ & $\begin{array}{c}\text { 内 前 膊 } \\
(\%)\end{array}$ & $(\%)^{\text {掌 }}$ \\
\hline $3.0 \mathrm{ec}$ & & & $2(0.5)$ & & 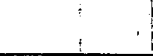 & \\
\hline fe & $\begin{array}{l}2(1.4) \\
1(3.7)\end{array}$ & & $1(0.2)$ & & & \\
\hline fc-gd & & & $\begin{array}{l}1(0.3) \\
1(0.2)\end{array}$ & $\begin{array}{l}1(1.0) \\
1(9.0)\end{array}$ & $\begin{array}{c}1(10.0) \\
1(1)\end{array}$ & . \\
\hline $\mathrm{gd}$ & & & $\begin{array}{l}9(2.5) \\
1(0.2)\end{array}$ & $\begin{array}{l}9(8.8) \\
1(9.0)\end{array}$ & $\begin{array}{r}1(1.0) \\
1(10.0)\end{array}$ & \\
\hline hd & & & $\begin{array}{l}1(0.3) \\
1(0.2)\end{array}$ & & & \\
\hline $3.25 \mathrm{gd}$ & & & $1(0.3)$ & & & \\
\hline $3.5 \mathrm{ec}$ & $\begin{array}{r}3(2.2) \\
3(11.1)\end{array}$ & & $4(0.4)$ & & & \\
\hline ec-fe & $\begin{array}{l}5(7.4) \\
2(8.6)\end{array}$ & & $2(0.6)$ & $1(1.0)$ & & \\
\hline fc-ec & $2(1.4)$ & & & & & \\
\hline $\mathrm{fc}$ & $\begin{array}{l}62(44.6) \\
11(40.8)\end{array}$ & & $\begin{array}{r}7(1.9) \\
12(2.8)\end{array}$ & $3(3.0)$ & $3(2.9)$ & \\
\hline fc-gd & $\begin{array}{r}13(12.9) \\
4(14.8)\end{array}$ & & $\begin{array}{r}12(23.1) \\
6(1.4) \\
\end{array}$ & $\begin{array}{l}7(6.8) \\
1(9.0)\end{array}$ & $\begin{array}{r}3(2.9) \\
1(10.0)\end{array}$ & \\
\hline $\mathrm{gd}-\mathrm{fc}$ & & & $3(0.8)$ & $3,3.0)$ & & \\
\hline
\end{tabular}




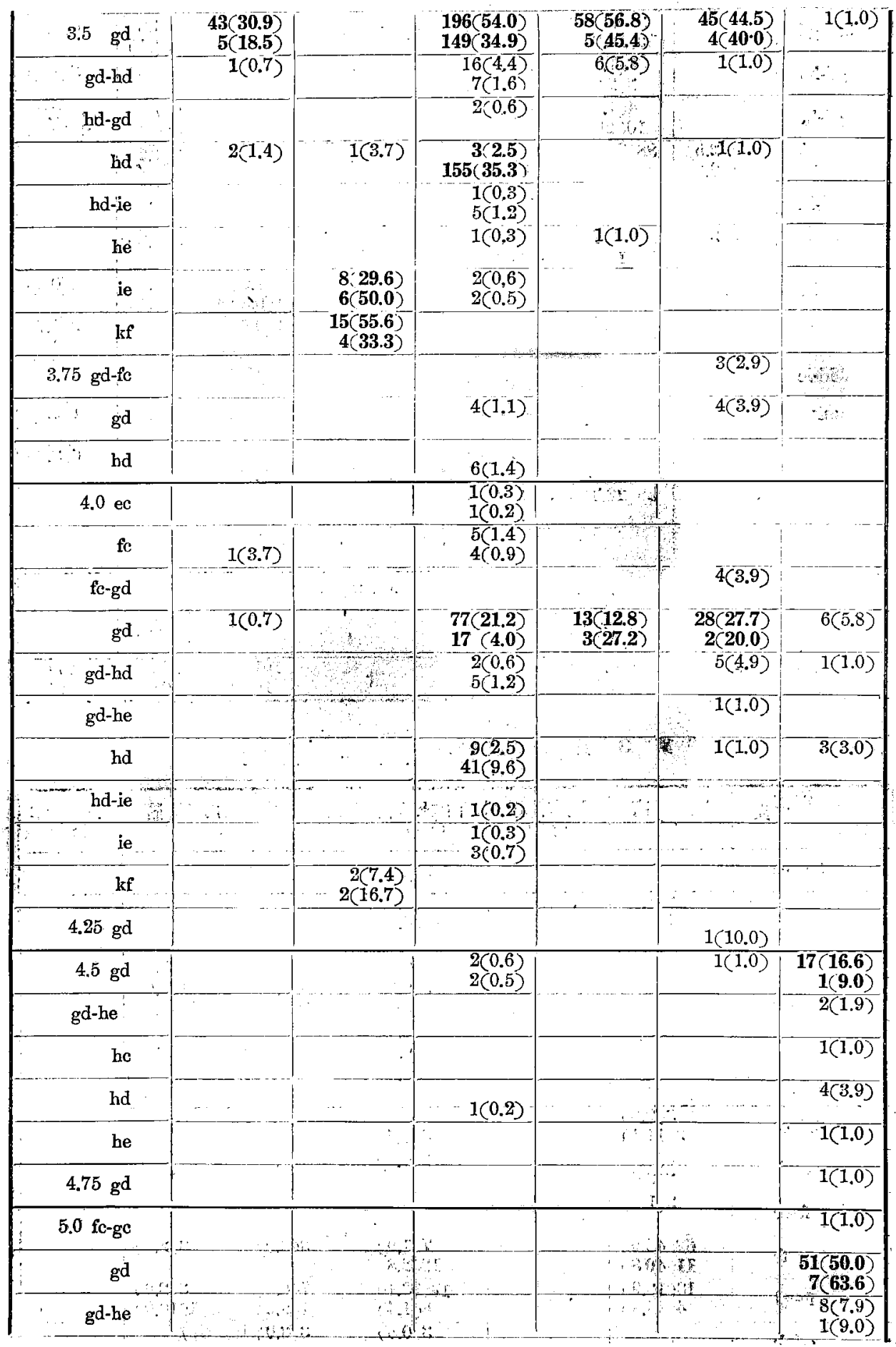




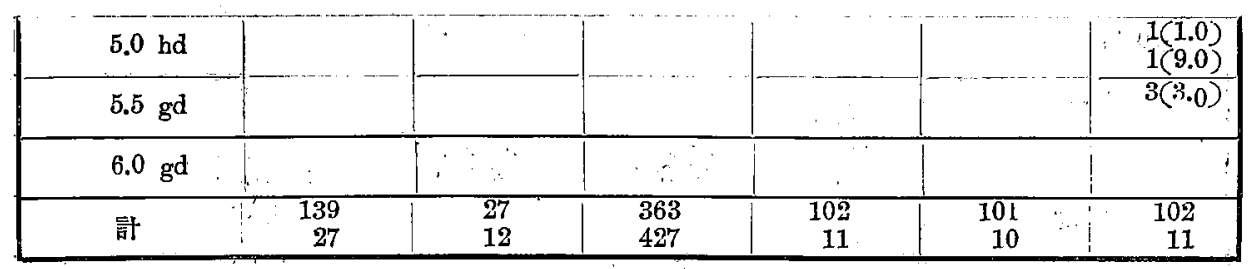

第 4 表 (上肢外側) 卡段……喜年期

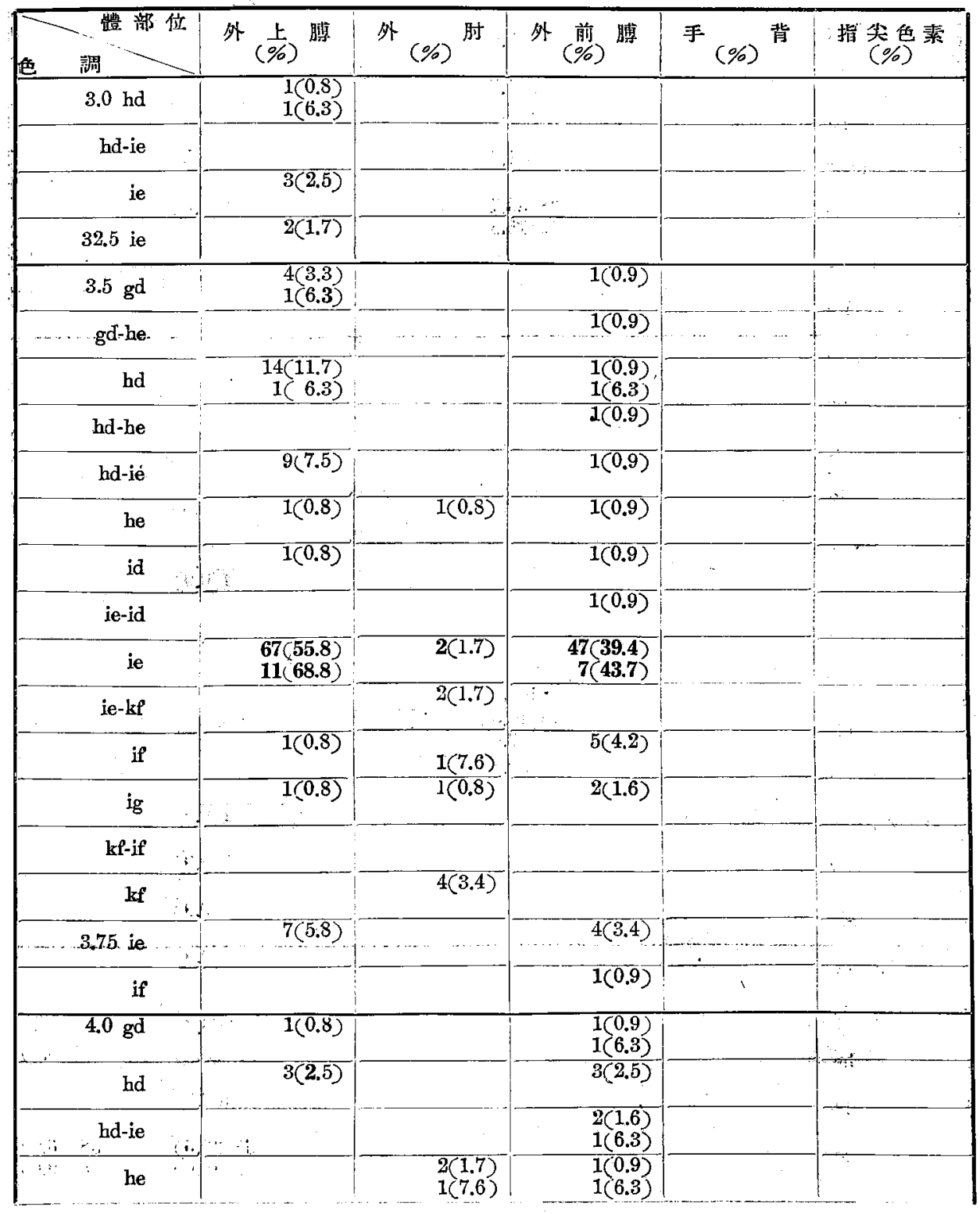




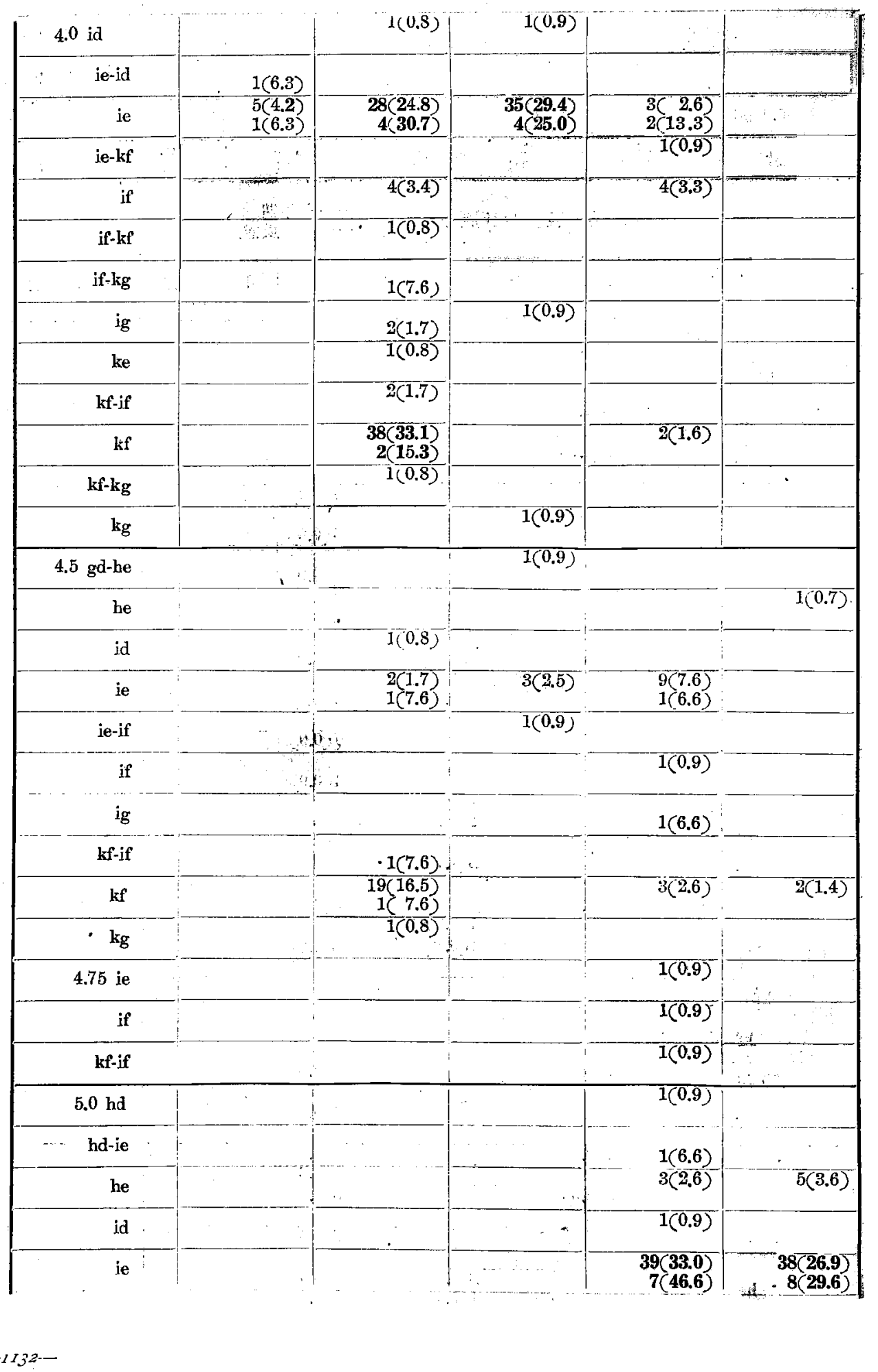




\begin{tabular}{|c|c|c|c|c|c|}
\hline 5.0 if & 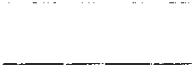 & + & $1(0.9)$ & $\begin{array}{r}21(17.7) \\
2(13.3) \\
\end{array}$ & $\begin{array}{r}7(4.9) \\
2(7.4) \\
\end{array}$ \\
\hline if -kf & & . & .. & $\therefore \quad 1(0.9)$ & : \\
\hline ig. & & & & $\overline{1(0.9)}$ & \\
\hline ke & & & & $1(0.9)$ & \\
\hline kf-ke & & & & $1(0.9)$ & \\
\hline $\mathrm{kf}$ & & $1(0.8)$ & & $\overline{13}(11.0)$ & $\begin{array}{l}1(5.2) \\
2(7.4)\end{array}$ \\
\hline kf-kg & & $\therefore \quad \therefore$ & & $1(0.9)$ & \\
\hline $\mathbf{k g}$ & & & & $2(1.6)$ & \\
\hline $5.5 \mathrm{hd}$ & . & a & & $\ldots$ & $1(0.7)$ \\
\hline ie & $\because$ & & & $2(1.6)$ & $\begin{array}{r}30(21.2) \\
6(22.2) \\
\end{array}$ \\
\hline if & & . & & 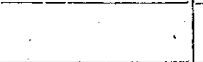 & $\begin{array}{l}2(1.4) \\
1(3.7)\end{array}$ \\
\hline $\mathbf{k f}$ & & . & . & . & $6(5.2)$ \\
\hline $.6 .0 \mathrm{hd}$ & & & & & $2(1.4)$ \\
\hline ie & - & & & $3(2.6)$ & $\begin{array}{r}35(24.8) \\
7(25.9)\end{array}$ \\
\hline$\therefore$ & & & $\cdot$ & $\begin{array}{r}1(0.9) \\
10(6.6)\end{array}$ & $1(0.7)$ \\
\hline $\mathrm{kf}$ & & & & & $\begin{array}{l}5(3.6) \\
1(3.7)\end{array}$ \\
\hline $\mathrm{kg}$ & & & 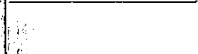 & $1(0.9)$ & \\
\hline 棓 & $\begin{array}{r}120 \\
16 \\
\end{array}$ & $\begin{array}{r}115 \\
13 \\
\end{array}$ & \begin{tabular}{|r|r|}
119 \\
10
\end{tabular} & $\begin{array}{r}118 \\
15 \\
\end{array}$ & $\begin{array}{r}141 \\
27 \\
\end{array}$ \\
\hline
\end{tabular}

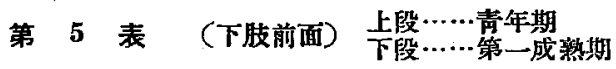

\begin{tabular}{|c|c|c|c|c|c|c|}
\hline 色铜 & $\begin{array}{c}\text { 前大 腿 } \\
(\%)\end{array}$ & $(\%)$ & $\begin{array}{c}\text { 前 下 腿 } \\
(\%)\end{array}$ & 外 $(\%)^{\text {踝 }}$ & 足 $(\%)^{\text {背 }}$ & $\begin{array}{c}\text { 趾尖色素 } \\
(\%)\end{array}$ \\
\hline $3.0 \mathrm{gd}-\mathrm{fc}$ & $1(4.4)$ & & & & & \\
\hline gd-he & $1(0.8)$ & 1 & & & & \\
\hline . hd-ie & $1(0.8)$ & & & & & \\
\hline 3.25 hd-ie & $1(0.8)$ & . & & & & \\
\hline$\quad$ ie & & $\overline{1(0.8)}$ & & & & \\
\hline $3.5 \mathrm{gd}$ & $\begin{array}{l}2(1.6) \\
1(4.4)\end{array}$ & & & & 7 & \\
\hline$\ldots . .$. gd-he & $2(1.6)$ & & $1(0.8)$ & 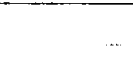 & $\cdots$ & \\
\hline hd & $\begin{array}{l}5(4.1) \\
1(4.4) \\
\end{array}$ & & $1(0.8)$ & & & $\cdots$ \\
\hline hd-ie' & $\begin{array}{l}1(0.8) \\
1(4.4)\end{array}$ & & & & $\therefore$ & \\
\hline he & & & & & & $\begin{array}{r}1(0.6) \\
1(2.6)\end{array}$ \\
\hline
\end{tabular}




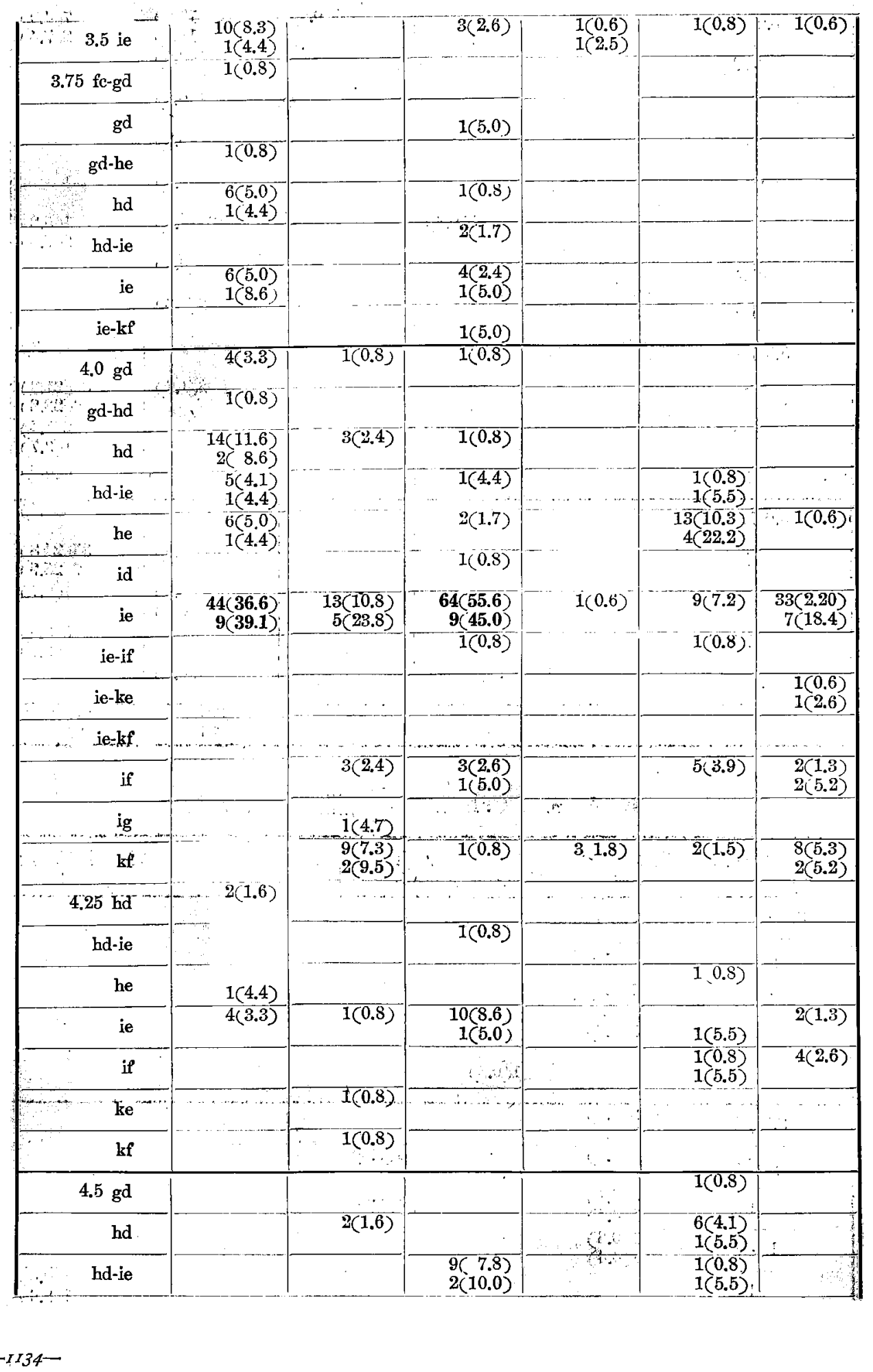




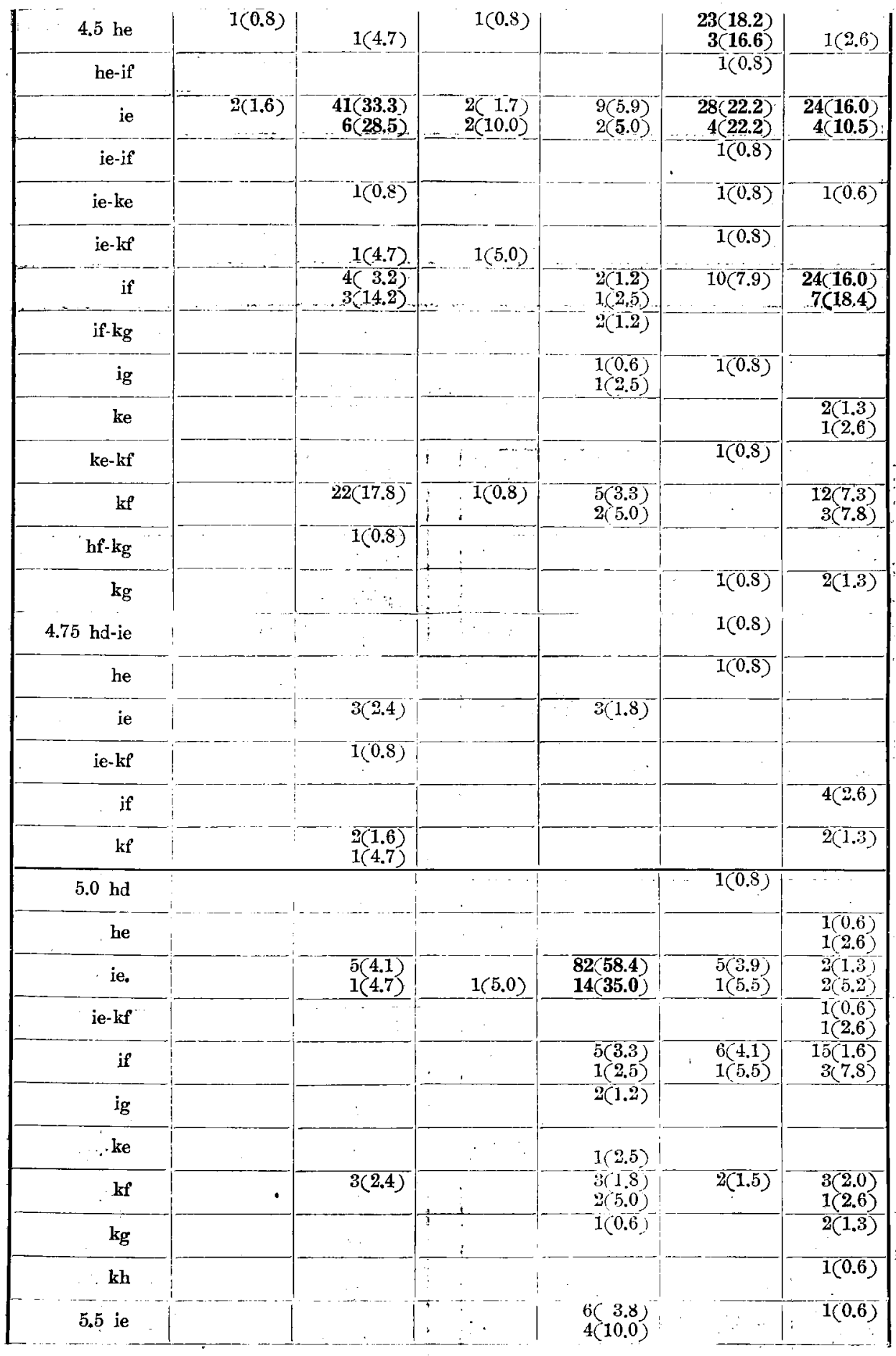




\begin{tabular}{|c|c|c|c|c|c|c|}
\hline 5.5 if & & & & $1(0.6)$ & & $1(2,6)$ \\
\hline ig & & & & $\begin{array}{l}1(0.6) \\
1(2.5)\end{array}$ & & \\
\hline kf & & & & $1(0,6)$ & & \\
\hline $6.0 \mathrm{ie}$ & & & & $\begin{array}{r}23(14.8) \\
8(20.0)\end{array}$ & . & \\
\hline ig & & & & $\begin{array}{l}1(0.6) \\
1(2.5)\end{array}$ & & \\
\hline lkf & & & & $\begin{array}{l}1(0.6) \\
1(2.5)\end{array}$ & & \\
\hline 㨃 & $\begin{array}{r}120 \\
23\end{array}$ & $\begin{array}{r}123 \\
21\end{array}$ & $\begin{array}{r}115 \\
20\end{array}$ & $\begin{array}{r}154 \\
40\end{array}$ & $\begin{array}{r}126 \\
18\end{array}$ & $\begin{array}{r}150 \\
38\end{array}$ \\
\hline
\end{tabular}

第 6 表 （下肢後面）卡段……青第一年成熟期
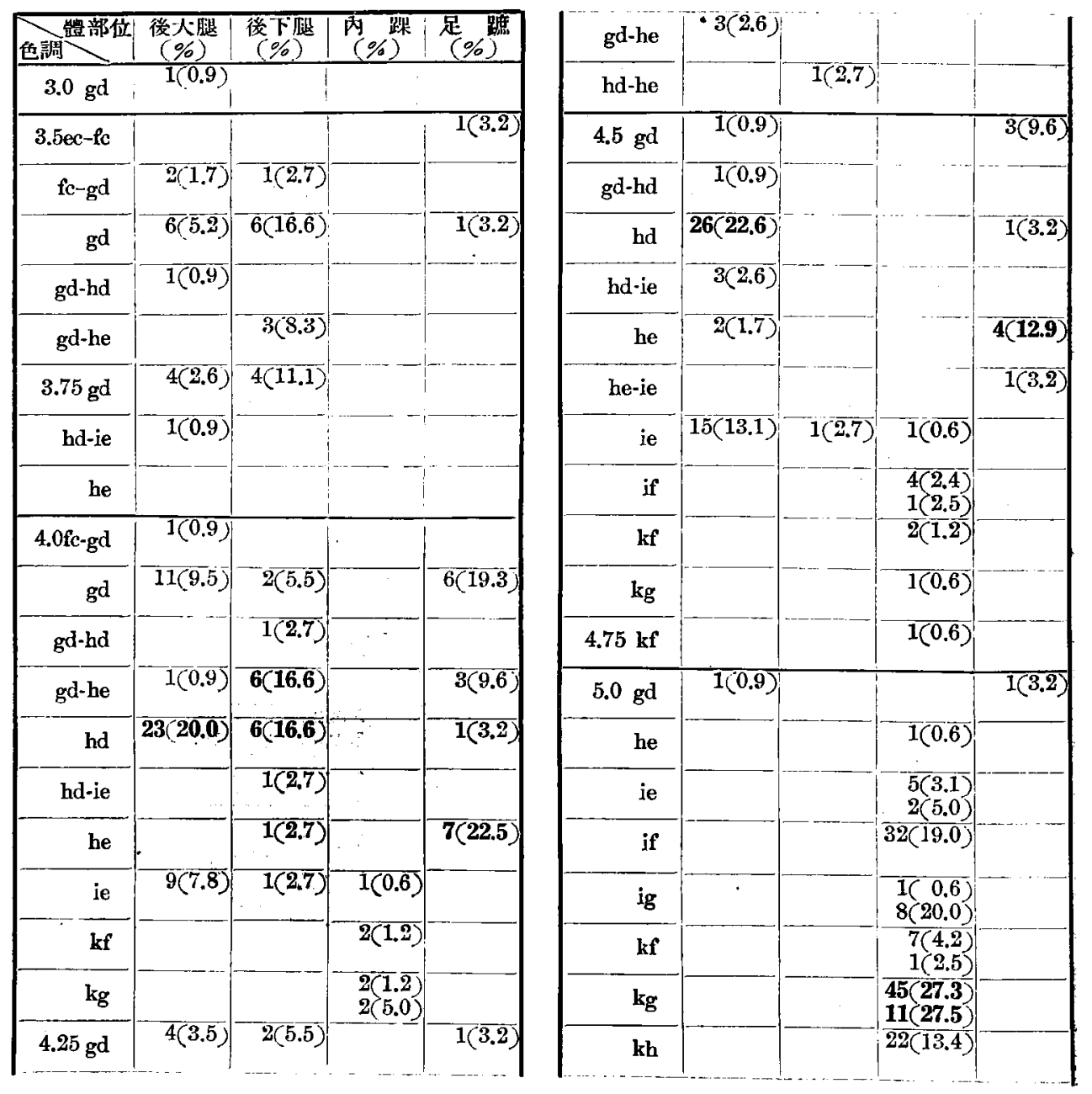


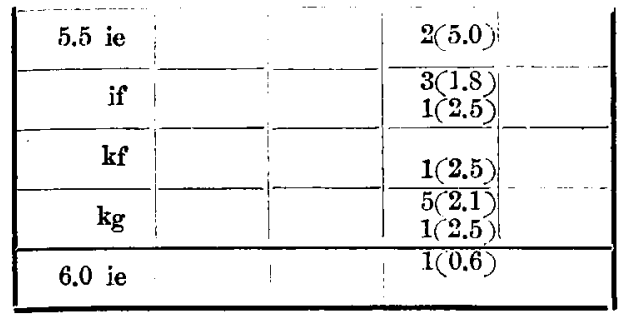

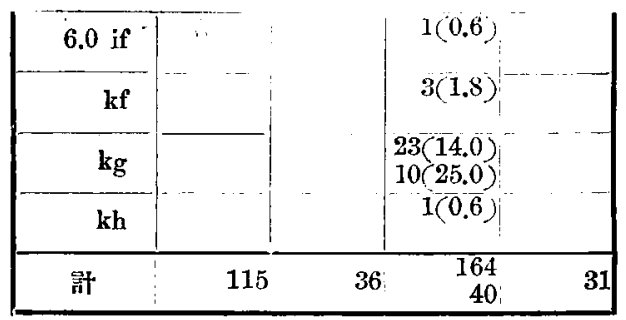

第 四章身體各部外皮(皮属)色調ノ分析各含有量

以上各體部位外皮(皮虚)色調 7 各基礎色下=色調分析含有量 7 杜列式(高サ八百分率 7 示ス) ヨ以テ表ハシ，之フ第 7-9 表及ビ第 1-3 圖=强ゲタリ。

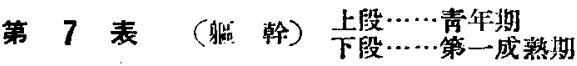

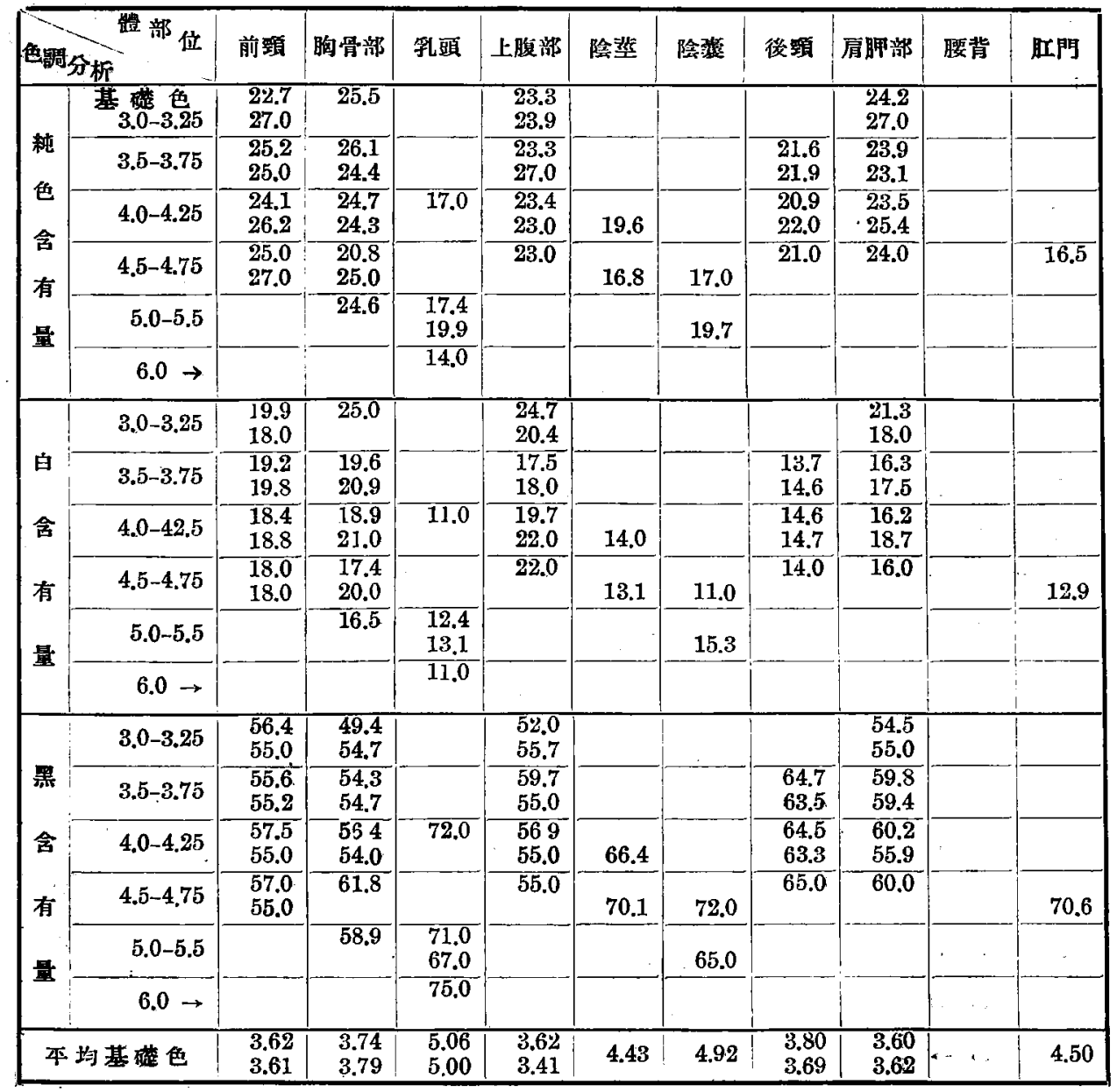


第 8 表 （上 肢）卡段……㝨第一成熟期

\begin{tabular}{|c|c|c|c|c|c|c|c|c|c|c|c|}
\hline \multicolumn{2}{|c|}{ 色調分析 } & 腋 简 & 內上膊 & 前 肘 & 內前膊 & 手 掌 & 外上膊 & 外 肘 & 外前膊 & 手 背 & 指 尖 \\
\hline & 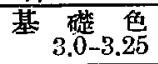 & $\begin{array}{l}28.0 \\
28.0\end{array}$ & $\begin{array}{l}24.9 \\
23.5\end{array}$ & $\begin{array}{l}23.3 \\
24.3\end{array}$ & $\begin{array}{l}23.0 \\
24.3\end{array}$ & & 22.0 & 21.0 & 24.0 & & \\
\hline & $3.5-3.75$ & $\begin{array}{l}25.7 \\
25.5\end{array}$ & $\begin{array}{l}22.1 \\
23.1\end{array}$ & $\begin{array}{l}23.6 \\
23.4\end{array}$ & $\begin{array}{l}23.6 \\
23.5\end{array}$ & $23 ; 0$ & $22 . \overline{0}$ & $\begin{array}{l}17.3 \\
14.0\end{array}$ & $\begin{array}{l}20.2 \\
21.8\end{array}$ & & \\
\hline 色 & $4.0-4.25$ & $\ldots 23.0$ & $24: 2$ & -23.0 & $=23.3$ & -23.9 & $23: \overline{2}$ & 78.4 & -21.2 & 17.2 & \\
\hline \multirow[t]{2}{*}{ 含 } & & 28.0 & 23.2 & 23.0 & 23.0 & 24.5 & & $\begin{array}{l}18.8 \\
17.7\end{array}$ & $\begin{array}{l}21.1 \\
20.1\end{array}$ & $\frac{21.0}{19.0}$ & 17.0 \\
\hline & $4.5-4.75$ & & 23.0 & & & 23.0 & & 17.8 & & 14.5 & \\
\hline & $5.0-5.5$ & & & & & $\begin{array}{l}22.8 \\
23.6\end{array}$ & & 17.0 & 14.0 & $\begin{array}{l}18.2 \\
19.9\end{array}$ & $\begin{array}{l}19.8 \\
19.5\end{array}$ \\
\hline & $6.0 \rightarrow$ & & & & & 23.0 & & & & $\begin{array}{l}17.6 \\
14.0\end{array}$ & $\begin{array}{l}20.7 \\
20.5\end{array}$ \\
\hline \multirow{2}{*}{ 白 } & $3.0-3.25$ & $\begin{array}{l}28.0 \\
28.0\end{array}$ & $\begin{array}{l}20.3 \\
21.9\end{array}$ & $\begin{array}{l}22.3 \\
23.5\end{array}$ & $\begin{array}{l}22.0 \\
23.5\end{array}$ & & 14.7 & 14.0 & 16.0 & & \\
\hline & $3.5-3.75$ & $\begin{array}{l}25.8 \\
27.3\end{array}$ & 20.4 & 22.5 & $\begin{array}{l}22.5 \\
23.6\end{array}$ & $2 \overline{2} .0$ & 15.0 & $\begin{array}{l}12.9 \\
14.0\end{array}$ & 14.0 & & \\
\hline \multirow[t]{2}{*}{ 含 } & $40-425$ & 22.0 & 19.7 & 22.0 & 22.0 & 20.6 & $16 . \overline{2}$ & 13.7 & 14.6 & 13.3 & \\
\hline & $45-475$ & 28.0 & $\frac{21.4}{20.7}$ & $2 Z .0$ & $\overline{2} \overline{2} \overline{2.0}$ & 21.7 & & $\begin{array}{l}13.0 \\
11.7\end{array}$ & $\frac{16.0}{15 . \dot{z}}$ & $\frac{14.0}{13.3}$ & 13.3 \\
\hline \multirow[t]{2}{*}{ 有 } & $4.0=4.60$ & 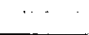 & 22.0 & 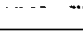 & & 22.0 & & 12.5 & & 14.0 & \\
\hline & $5.0-5.5$ & & & . & 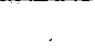 & $\begin{array}{l}21.7 \\
21.4\end{array}$ & & 11.0 & 14.0 & $\begin{array}{l}13.5 \\
14.2\end{array}$ & $\begin{array}{l}13.9 \\
13.7\end{array}$ \\
\hline 量 & $6.0 \rightarrow$ & & & & & 22.0 & & & & $\begin{array}{l}13.4 \\
140\end{array}$ & $\begin{array}{l}16.2 \\
13.6\end{array}$ \\
\hline \multirow{2}{*}{ 黑 } & $3.0-3.25$ & $\begin{array}{l}44.0 \\
44.0\end{array}$ & $\begin{array}{l}54.8 \\
546\end{array}$ & 54.4 & 55.0 & & 63.3 & 65,0 & 60.0 & & \\
\hline & $3.5-3.75$ & 48.5 & 58.5 & $\begin{array}{l}53.9 \\
541\end{array}$ & 53.9 & $5 \overline{5} .0$ & $63 . \overline{0}$ & $\begin{array}{l}69.8 \\
72.0\end{array}$ & $\begin{array}{l}63.8 \\
63.7\end{array}$ & & \\
\hline \multirow[t]{2}{*}{ 含 } & $4.0-4.2 \bar{\Sigma}$ & 55.0 & 56.9 & 55.0 & 54.7 & 55.5 & 60.3 & 67.9 & 64.2 & 69.5 & \\
\hline & $4.5-4.75$ & & $\begin{array}{l}55.0 \\
55.0\end{array}$ & & 55.0 & $\begin{array}{l}53.8 \\
55.0\end{array}$ & & $\begin{array}{l}70.6 \\
69.7\end{array}$ & 64.7 & $\begin{array}{r}67.7 \\
71.5\end{array}$ & $\overline{69.7}$ \\
\hline 有. & $5.5-5.5$ & & & & & $\begin{array}{l}55.5 \\
55.0\end{array}$ & & 72.0 & 72.0 & $\begin{array}{l}68.3 \\
65.9\end{array}$ & $\begin{array}{l}66.3 \\
66.8\end{array}$ \\
\hline 量 & $6.0 \rightarrow$ & & & & & 55.0 & & & & $\begin{array}{l}69.0 \\
72.0\end{array}$ & $\begin{array}{l}63.1 \\
65.9\end{array}$ \\
\hline \multicolumn{2}{|c|}{ 本均基礎色 } & $\begin{array}{l}3.49 \\
3.50\end{array}$ & \begin{tabular}{l|l}
3.59 \\
3.62
\end{tabular} & $\begin{array}{l}3.51 \\
3.55\end{array}$ & $\begin{array}{l}3.72 \\
3.58\end{array}$ & $\begin{array}{l}4.80 \\
5.0\end{array}$ & 3.53 & $\begin{array}{l}4.07 \\
4.08\end{array}$ & $\begin{array}{l}3.72 \\
3.69\end{array}$ & $\begin{array}{l}4.90 \\
4.87\end{array}$ & $\begin{array}{l}5.43 \\
5.43\end{array}$ \\
\hline
\end{tabular}

\section{9 表（下 肢） 卡段……喜第一成熟期}

\begin{tabular}{|c|c|c|c|c|c|c|c|c|c|c|c|}
\hline \multicolumn{2}{|c|}{ 色調分析 部 } & 前大配 & 滕 & 前下腿 & 外 踝 & 足 背 & 趾尖 & 後大腿 & 後下腿 & 內踝 & 足 蹠 \\
\hline \multirow[b]{2}{*}{ 純 } & 基 礎 & $\begin{array}{l}24.3 \\
25.5 .\end{array}$ & & & & & & 23.0 & & & \\
\hline & $3.5-3.75$ & $\begin{array}{l}24.0 \\
22.6\end{array}$ & & $\begin{array}{l}22.4 \\
23.0\end{array}$ & & & 17.0 & 23.6 & 22.5 & & 21.5 \\
\hline \multirow{4}{*}{$\begin{array}{l}\text { 含 } \\
\text { 有 } \\
\text { 量 }\end{array}$} & $4.0-4.25$ & $\begin{array}{l}22.2 \\
21.5\end{array}$ & 18.4 & $\begin{array}{l}21.0 \\
20.4\end{array}$ & 21.0 & 18.2 & 19.3 & 24.2 & 22.8 & 11.0 & 20.4 \\
\hline & $4.5-4.75$ & $19.7^{-}$ & 18.4 & $\begin{array}{l}22.5 \\
21.8 \\
\end{array}$ & 16.3 & 20.6 & 17.1 & 25.3 & 21.0 & 14.0 & 20.3 \\
\hline & $5.0-5.5$ & & 21.0 & 8.0 & 19.9 & 17.5 & 16.8 & 23.0 & & 12.1 & 23.0 \\
\hline & $6.0 \rightarrow$ & & & & 19.3 & & & & & 17.0 & \\
\hline
\end{tabular}




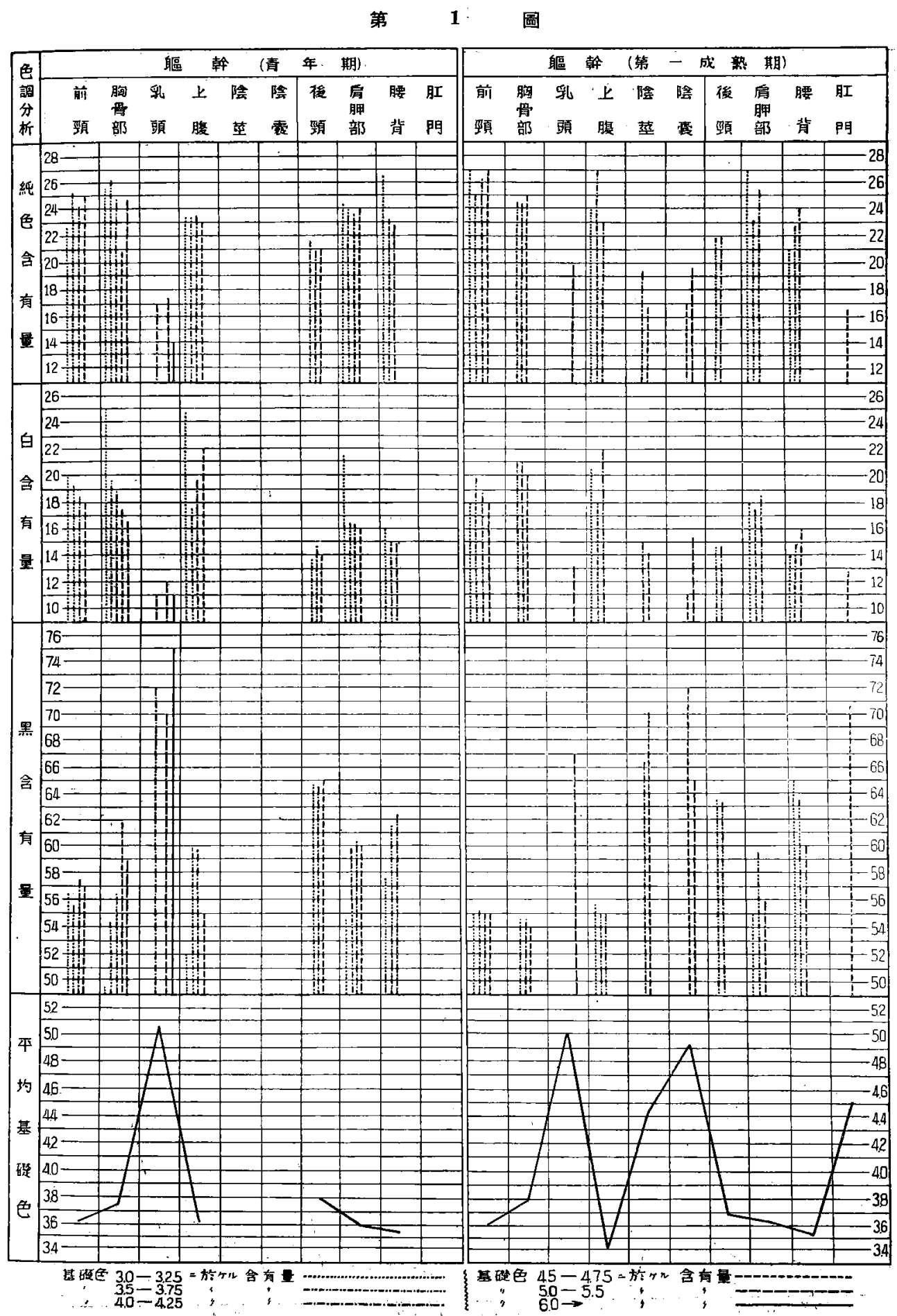




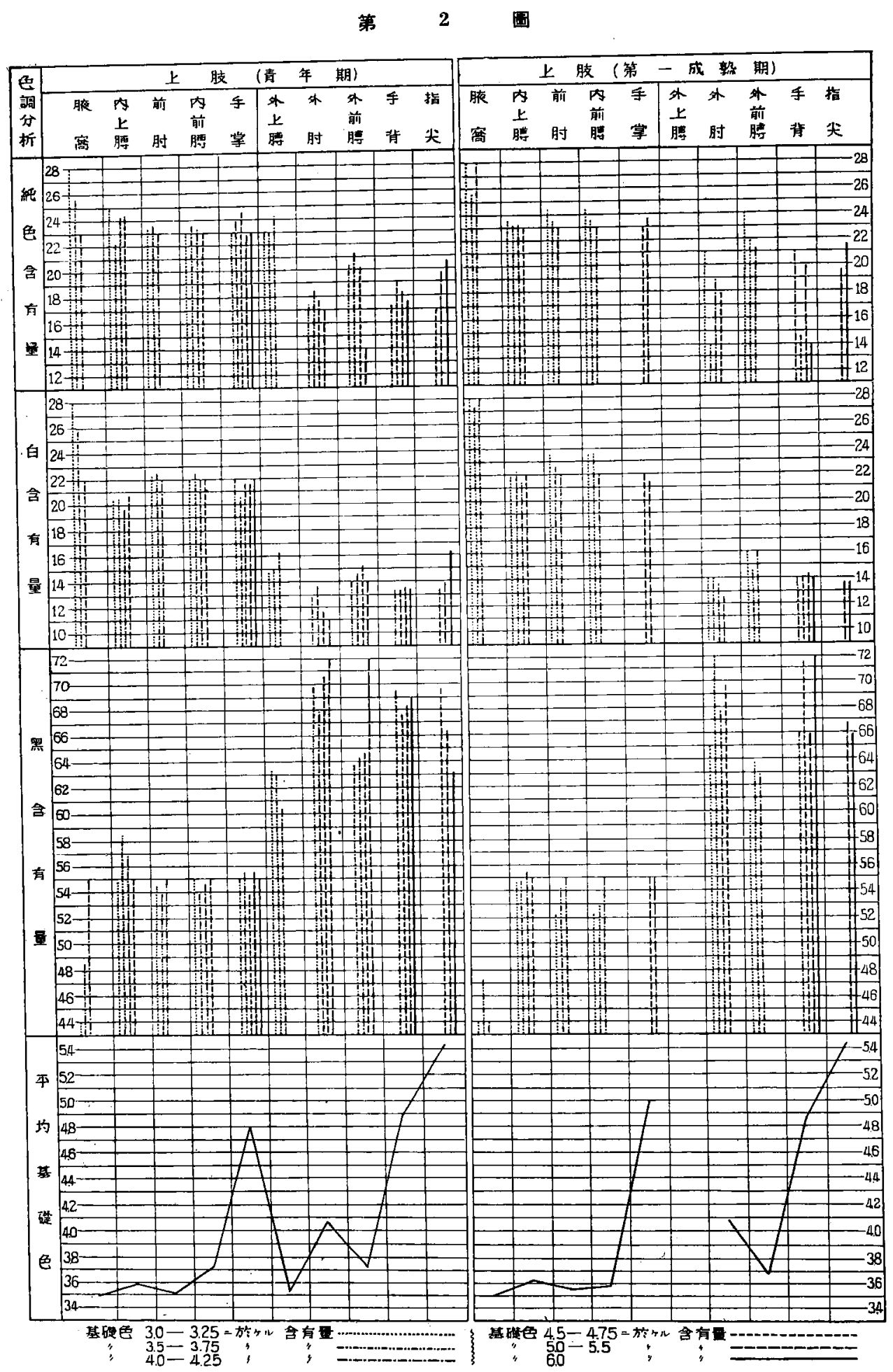




\section{第 3 團}

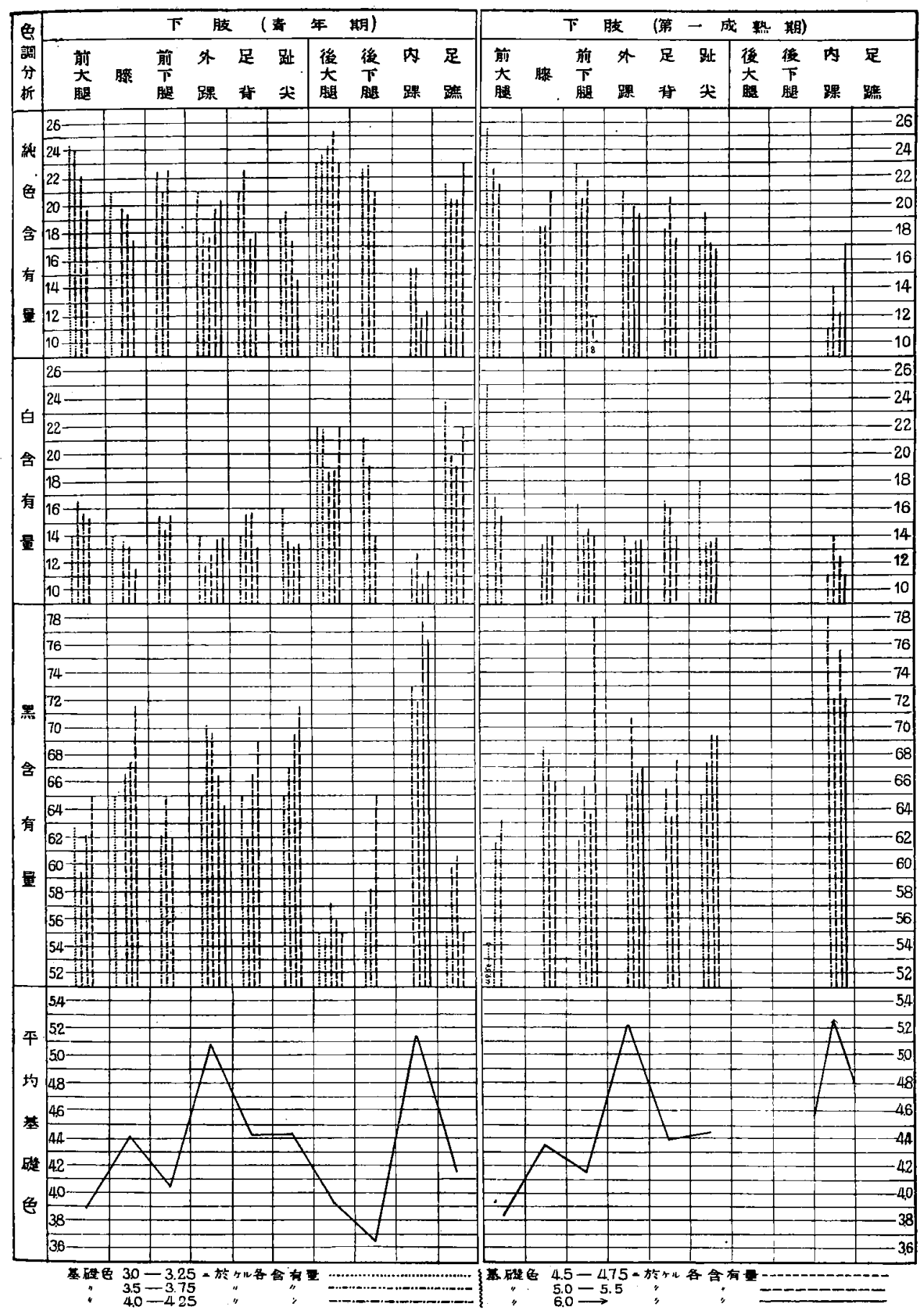




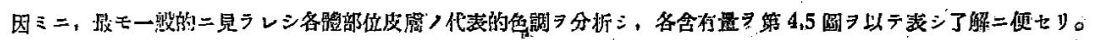

第

圖

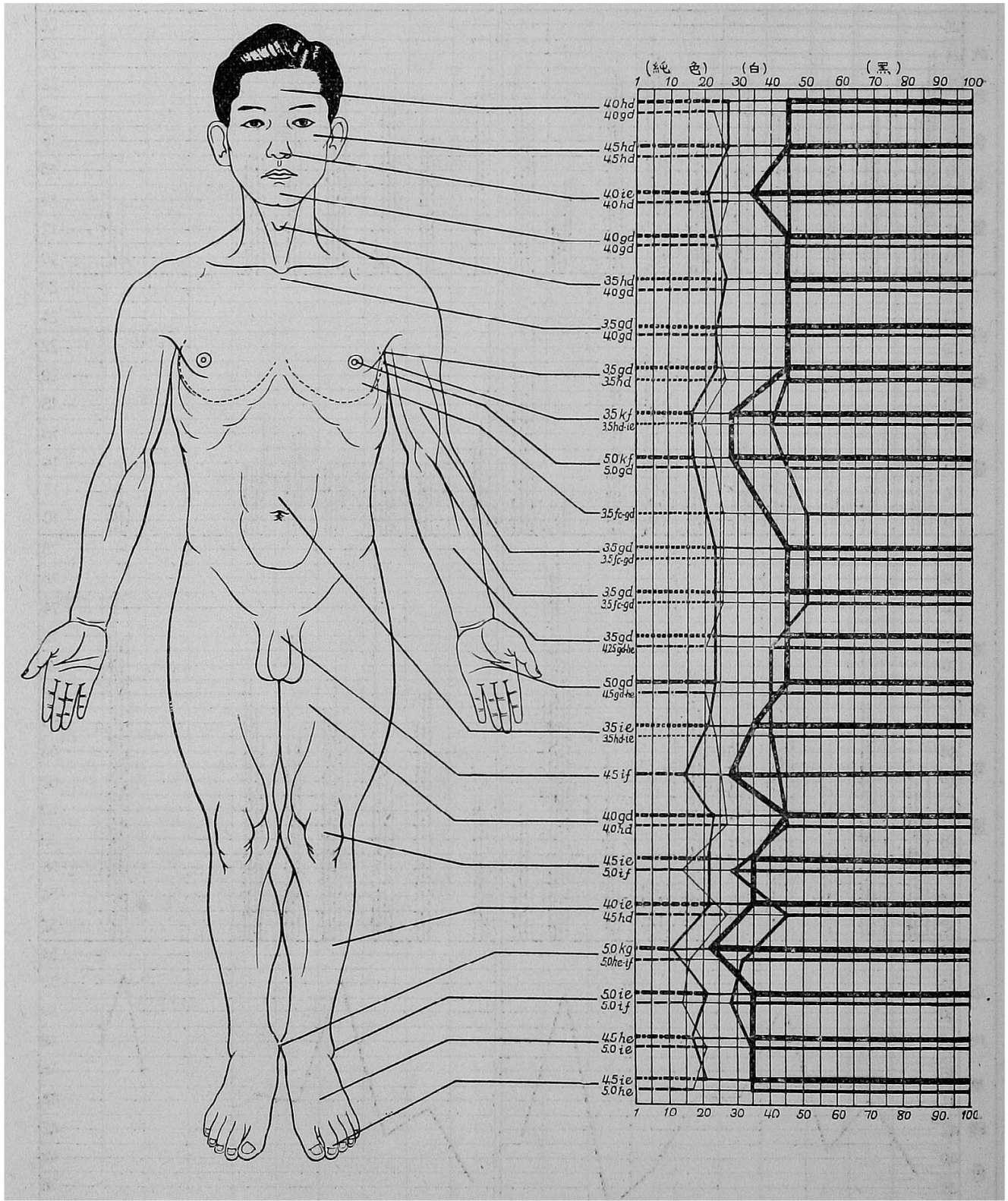




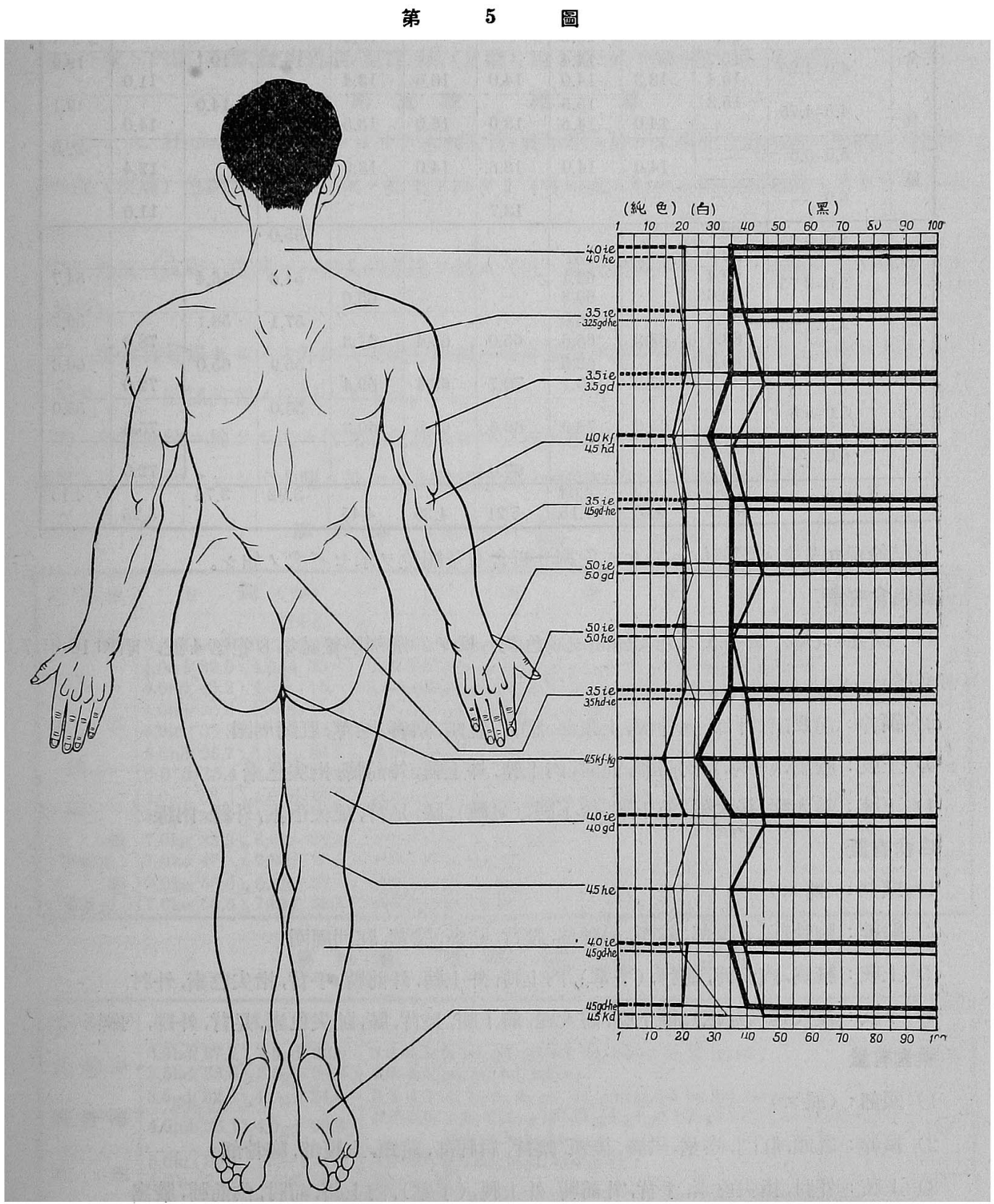

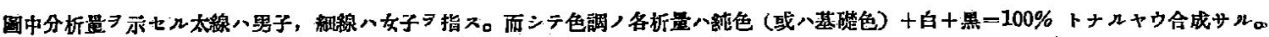

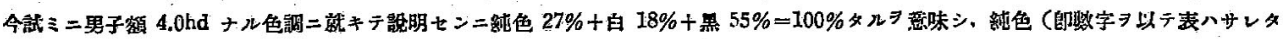

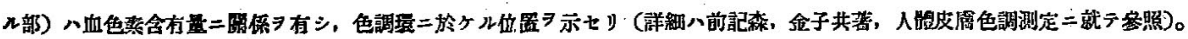




\begin{tabular}{|c|c|c|c|c|c|c|c|c|c|c|c|}
\hline \multirow{2}{*}{ 白 } & $3.0-3.25$ & $\begin{array}{l}\mathbf{1 4 . 0} \\
\mathbf{2 5 . 0}\end{array}$ & & & & & & 22.0 & & & \\
\hline & $3.5-3.75$ & $\begin{array}{l}16.6 \\
16.8 \\
\end{array}$ & & $\begin{array}{l}1.5 . \overline{0} \\
16.2\end{array}$ & & & 18.0 & 21.8 & 21.1 & & 28.3 \\
\hline 舍 & $4.0-4.25$ & $\begin{array}{l}15.7 \\
15.4\end{array}$ & 13.3 & $\begin{array}{l}14.4 \\
14.0\end{array}$ & 14.0 & 16.5 & 13.4 & 18.7 & 19.1 & 11.0 & 19.9 \\
\hline \multirow[t]{2}{*}{ 有 } & $4.5-4.75$ & $15 . \overline{3}$ & 14.0 & $\begin{array}{l}15.5 \\
14.5\end{array}$ & 13.0 & 16.0 & 13.5 & 18.8 & 14.0 & 14.0 & 19.1 \\
\hline & $5.0-5.5$ & & 14.0 & 14.0 & 13.6 & 14.0 & 13.9 & 22.0 & & 12.4 & $22 . \overline{0}$ \\
\hline 量 & $6.0 \rightarrow$ & & & & 13.7 & & & & & 11.0 & \\
\hline \multirow{2}{*}{ 黑 } & $3.0-3.25$ & $\begin{array}{l}62.7 \\
49.5\end{array}$ & & & & & & 55.0 & & & \\
\hline & $3.5-3.7 \overline{5}$ & $\begin{array}{l}59.4 \\
60.6 \\
\end{array}$ & & $\begin{array}{l}62.1 \\
60.8\end{array}$ & & & 65.0 & 54.6 & 56.4 & & 54.7 \\
\hline 含 & $4.0-4.25$ & $\begin{array}{r}62.1 \\
63.1 \\
\end{array}$ & 68.3 & $\begin{array}{r}65.0 \\
65.6 \\
\end{array}$ & 65.0 & 65.4 & 67.3 & 57.1 & 58.1 & 78.0 & 59.7 \\
\hline \multirow[t]{2}{*}{ 有 } & $4.5-4.75$ & $6 \overline{5}, 0$ & 67.6 & $\begin{array}{l}62.0 \\
63.7\end{array}$ & 70.7 & 63.4 & 69.4 & 55.9 & 65.0 & 72.0 & $\overline{60.6}$ \\
\hline & $5.0-5.5$ & & 65.0 & 78.0 & 66.5 & 68.5 & 69.3 & 55.0 & & 75.5 & 55.0 \\
\hline 量 & $6.0 \rightarrow$ & & & & 67.0 & & & & & 72.0 & \\
\hline \multicolumn{2}{|c|}{ 平均基整色 } & $\begin{array}{r}3.89 \\
3.53 \\
\end{array}$ & 4.35 & $\begin{array}{l}4.04 \\
4.15\end{array}$ & 5.21 & 4.39 & 4.45 & 3.92 & 3.74 & 5.25 & 4.15 \\
\hline
\end{tabular}

上記各表ョリ夫そ體部位ニ於ヶル色調分析含倠量順位タ示セバ次ノ如シ。 純色含有量

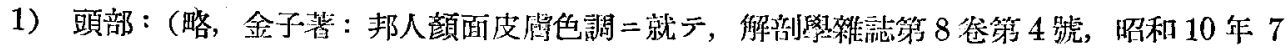
月參照)

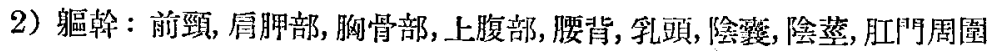

3)上肢：腋窝，(手掌)，內前膊, 前肘, 内上膊, 外上腺, 外前膊, 指尖色素

4) 下肢：前大腿, 後大腿, 前下腿, 後下腿, (足蹠), 滕, 足背, 距尖色素, 外踝, 冈踝

\section{白含有量}

1）頭部：(略ス)

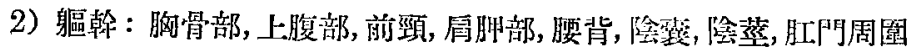

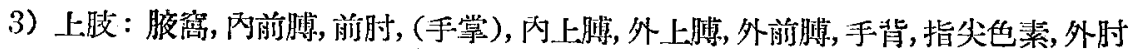

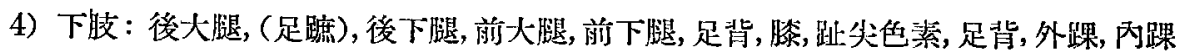

\section{黑含有量}

1) 頭部：(格天)

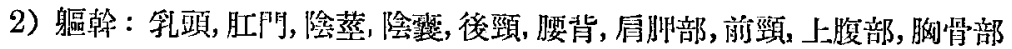

3）上肢：外肘, 指尖色素, 手背, 外前膊, 外上膊, (手掌), 內上膊, 前肘, 内前膊, 腋窝

4）下肢：丙踝, 外踝, 趾尖色溸, 膝, 足背, 前下腿, 前大腿, 後下腿，(足蹠), 後大腿

\section{基礎色}

1) 頭部：(略ス) 


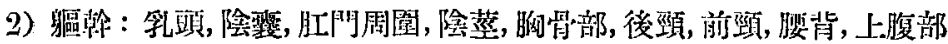

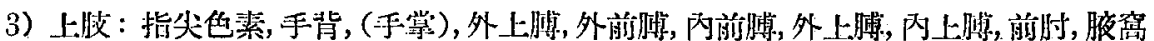

4）下肢：队踝, 外踝, 趾尖色素, 足背, 膝, (足蹠), 前下腿, 後下腿, 前大煺, 後大腿。

\section{第五章結果}

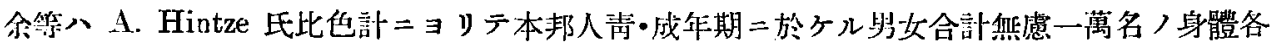

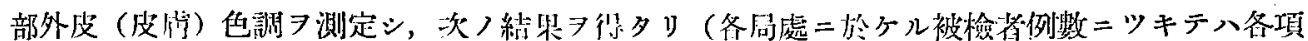
參照)。

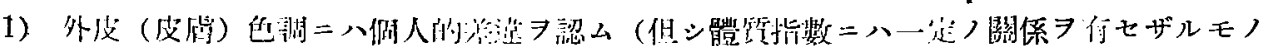
，如シ）。

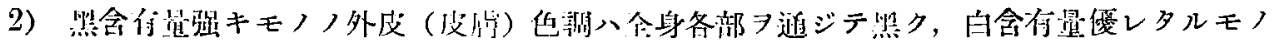
ニ於テハソノ關係前者ノ反對ナリトス。

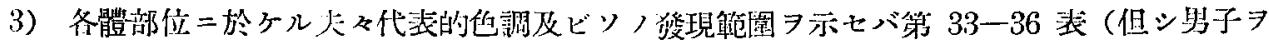

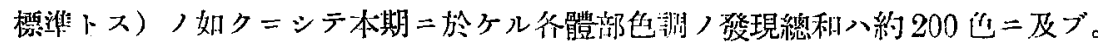

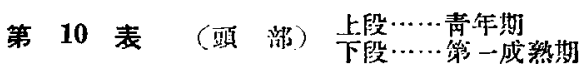

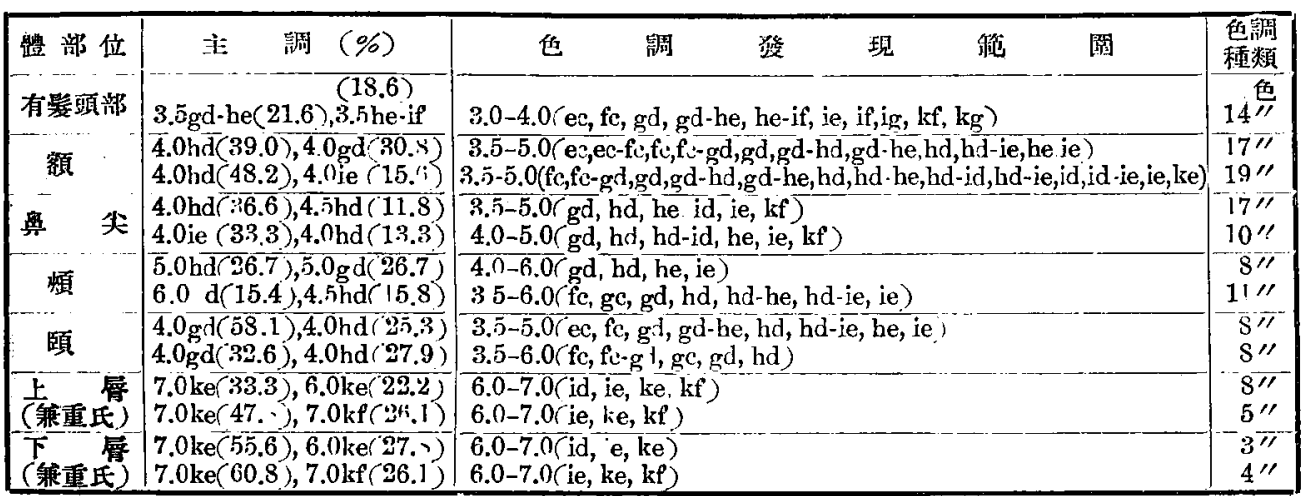

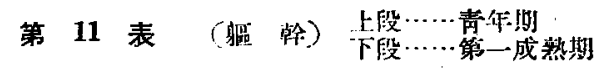

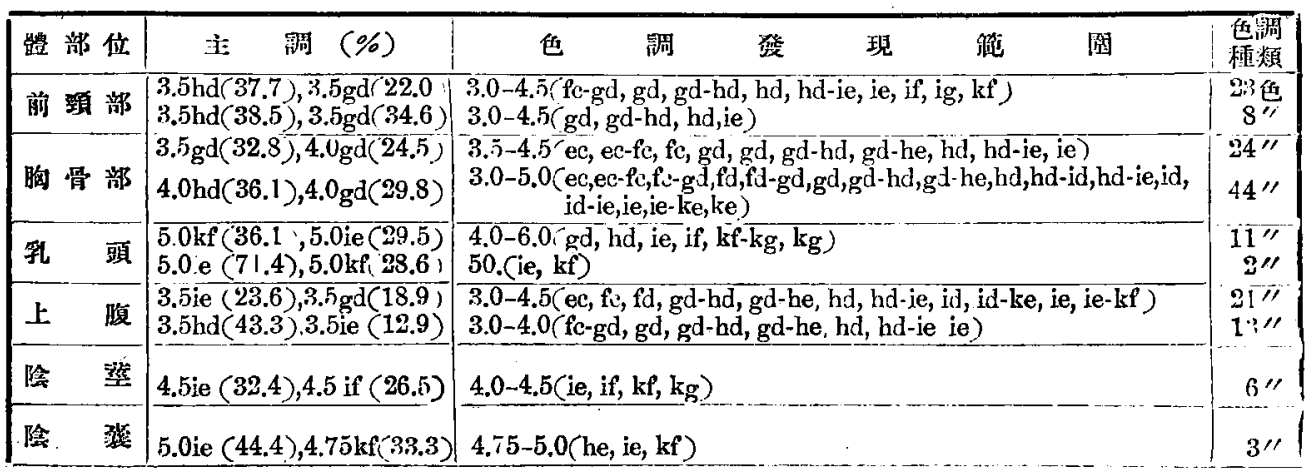




\begin{tabular}{|c|c|c|c|}
\hline 後频 & $\begin{array}{l}4.0 \mathrm{ie}(46.0), 3.5 \mathrm{ie}(34.1) \\
3.5 \mathrm{ie}(50.0), 4.0 \mathrm{ie}(31.3)\end{array}$ & $\begin{array}{l}3.5-4.5(\mathrm{hd}, \mathrm{hd}-\mathrm{ie}, \mathrm{id}, \mathrm{ie}, \mathrm{kf}) \\
3.5-4.0(\mathrm{hd}, \mathrm{hd}-\mathrm{ie}, \mathrm{ie})\end{array}$ & 10色 \\
\hline 局 盰 部 & $\begin{array}{l}\text { 3.5hd(33.9), 35ie }(22.3) \\
\text { 3.5hd-ie(17.6)3.5 gd(13.2) }\end{array}$ & $\begin{array}{l}\text { 3.0-4.5(gd, gd-hd, gd-he, hd, hd-ie, id, ie) } \\
3.0-4.0, \mathrm{fc}-\mathrm{gd}, \mathrm{gd}, \mathrm{gd}-\mathrm{hd}, \mathrm{gd}-\mathrm{he}, \mathrm{bd-ie,ie,} \mathrm{ie-kf)}\end{array}$ & $\begin{array}{l}24 / \prime \\
16^{\prime \prime}\end{array}$ \\
\hline 腰 & $\begin{array}{l}35 \mathrm{ie}(36.7), 3.5 \mathrm{hd}-\mathrm{ie}(20.0) \\
35 \mathrm{ie}(31.3), 3.5 \mathrm{hd}-\mathrm{ie}(25.0)\end{array}$ & $\begin{array}{l}\text { 3.0-4.0(gd-hd,gd he,hd,hd-id,hd-ie,he,id,id,id-ke,ie-ke,ie-id,ie,iekf) } \\
\text { 3.0-4.0(hd,hd-ie, id-ie,ie,ie-ke) }\end{array}$ & $\begin{array}{r}20^{\prime \prime} \\
9^{\prime \prime}\end{array}$ \\
\hline 䢸門周槳 & $4.5 \mathrm{kf}(33.3), 4.5 \mathrm{ie}(20.8)$ & 4.5 (hd-ie, he, ie, if, $\mathrm{kf}, \mathrm{kg}$ ) & $6^{\prime \prime}$ \\
\hline
\end{tabular}

\section{第 12 表 (上 肢) 上段……青年期}

\begin{tabular}{|c|c|c|c|}
\hline 體 部 位 & 輱 (\%) & 筑 & $\begin{array}{l}\text { 魚調 } \\
\text { 種類 }\end{array}$ \\
\hline 腋䈑 & $\begin{array}{l}3.5 \mathrm{fc}(44.6), 3.5 \mathrm{gd}(30.9) \\
3.5 \mathrm{fc}(40.8), 3.5 \mathrm{fcgd}(18.5)\end{array}$ & $\begin{array}{l}3.0-4.0(e c, e c-f c, f c, f c-g d, g d, g d-h d, h d) \\
3.0-4.0(e c, e c-f c, f c, f-g d, g d)\end{array}$ & 10色 \\
\hline 內上䐜 & $\begin{array}{l}3.5 \mathrm{gd}(54.0), 4.0 \mathrm{gd}(21.2) \\
3.5 \mathrm{hd}(35.3), 3.5 \mathrm{gd}(34.9)\end{array}$ & $\begin{array}{l}3.0-4.5 \text { (ec, ec-fc, fc, fe-gd, gd, gd-hd, hd, hd-ie, he, le) } \\
3.0-4.5 \text { (ec, fc, fc-gd, gd, gd-hd, hd, hd-ie, ie) }\end{array}$ & $23^{\prime \prime}$ \\
\hline 內 肘 & $\begin{array}{l}3.5 \operatorname{gd}(56.8), 4.0 \operatorname{gd}(12.7) \\
3.5 \operatorname{gd}(45.4), 4.0 \operatorname{gd}(27.2)\end{array}$ & $\begin{array}{l}3.0-4.0(\mathrm{ec}-\mathrm{fc}, \mathrm{fc}, \mathrm{fc}-\mathrm{gd}, \mathrm{gd}, \mathrm{gd}-\mathrm{hd}, \mathrm{he}) \\
3.0-4.0(\mathrm{fc}-\mathrm{gd}, \mathrm{gd})\end{array}$ & $\begin{array}{r}10 \prime \prime \\
5 \prime \prime\end{array}$ \\
\hline 丙前膊 & $\begin{array}{l}3.5 \operatorname{gd}(44.6) 4.0 \operatorname{gd}(27.7) \\
3.5 \operatorname{gd} 40.0), 4.0 \operatorname{gd}(20.0)\end{array}$ & $\begin{array}{l}3.0-4.5(\mathrm{fc}, \mathrm{fc}-\mathrm{gd}, \mathrm{gd}, \mathrm{gd}-\mathrm{hd}, \mathrm{gd}-\mathrm{he}, \mathrm{hd}) \\
3.0-4.25(\mathrm{fc}-\mathrm{gd}, \mathrm{gd})\end{array}$ & $\begin{array}{r}14 / \prime \\
6 \prime \prime\end{array}$ \\
\hline 手学 & $\begin{array}{l}5.0 \operatorname{gd}(50.0), 4.5 \operatorname{gd}(16.6) \\
5.0 \operatorname{gd}(63.6), 4.5 \operatorname{gd}(9.1)\end{array}$ & $\begin{array}{l}3.5-6.0(\mathrm{fc}-\mathrm{gc}, \mathrm{gd}, \mathrm{gd}-\mathrm{he}, \mathrm{hc}, \mathrm{hd}, \mathrm{he}) \\
4.5-5.5(\mathrm{gd}, \mathrm{gd}-\mathrm{he}, \mathrm{hd})\end{array}$ & $\begin{array}{r}16^{\prime \prime} \\
5 \prime \prime\end{array}$ \\
\hline 外上膊 & $=3.5 \mathrm{ie}(50.8), 35 \mathrm{hd}(11.7)$ & 3.0-4.0(gd, hd, hd-ie, he, id, ie, if, ig) & $15^{\prime \prime}$ \\
\hline 外 & $\begin{array}{l}4.0 \mathrm{kf}(33.1), 4.0 \mathrm{ie}(24.8) \\
4.0 \mathrm{ie}(30.7), 4.0 \mathrm{kf}(19.3)\end{array}$ & $\begin{array}{l}3.5-5.0 \text { (he, id, ie, ie- } \mathrm{kf} \text {, if, if }-\overline{k f}, \text { ig, ke, } \mathrm{kf}-\mathrm{kg}, \mathrm{kg}) \\
3.0-4.5 \text { (he, ie, if, if-kf, if- } \mathrm{kg}, \mathrm{kf}, \mathrm{kg})\end{array}$ & $\begin{array}{r}21 " \prime \\
8 \prime \prime\end{array}$ \\
\hline 外前 膊 & $\begin{array}{l}3.5 \mathrm{ie}(39.8,4.0 \mathrm{e}(29.7) \\
3.5 \mathrm{ie}(43.8), 4.0 \mathrm{ie} 25.0)\end{array}$ & $\begin{array}{l}\text { 3.5-5.0 (gd, gd-he, hd, hd-ie, be, id, id-ie,ie, ie-if, if, if-kf,ig,kg) } \\
\text { 3.0-4.0(gd, hd, hd-ie, he, ie) }\end{array}$ & $\begin{aligned} 25 \prime \prime \prime \\
7 \prime \prime\end{aligned}$ \\
\hline 手 & $\begin{array}{l}5.0 \mathrm{ie}(33.1), 5.0 \mathrm{if}(17.8) \\
5.0 \mathrm{ie}(46.6), 50 \mathrm{if}(13.3)\end{array}$ & $\begin{array}{l}4.0-5.5 \text { (hd, he, id, ie, ie-kf, if, if-kf, kf, ig, ke, lke-kf, kf-kg, kg) } \\
4.0-6.0 \text {, hd-ie, ie, if, ig) }\end{array}$ & $\begin{array}{r}26 \overline{\prime \prime} \\
7 \prime \prime\end{array}$ \\
\hline 指少 & $\left|\begin{array}{l}5.0 \mathrm{ie}(27.0), 60 \mathrm{ie}(24.8) \\
5.0 \mathrm{ie}(29.6), 6.0 \mathrm{je}(25.9)\end{array}\right|$ & $\begin{array}{l}4.5-6.0(\mathrm{hd}, \mathrm{he}, \mathrm{ie}, \mathrm{if}, \mathrm{kf}) \\
5.0-6.0(\mathrm{ie}, \mathrm{if}, \mathrm{kf})\end{array}$ & $\mid \begin{array}{r}14 \prime \prime \\
7 \prime \prime\end{array}$ \\
\hline
\end{tabular}

\section{第 13 表 （下 肢）卡段……贲第一成熱期}

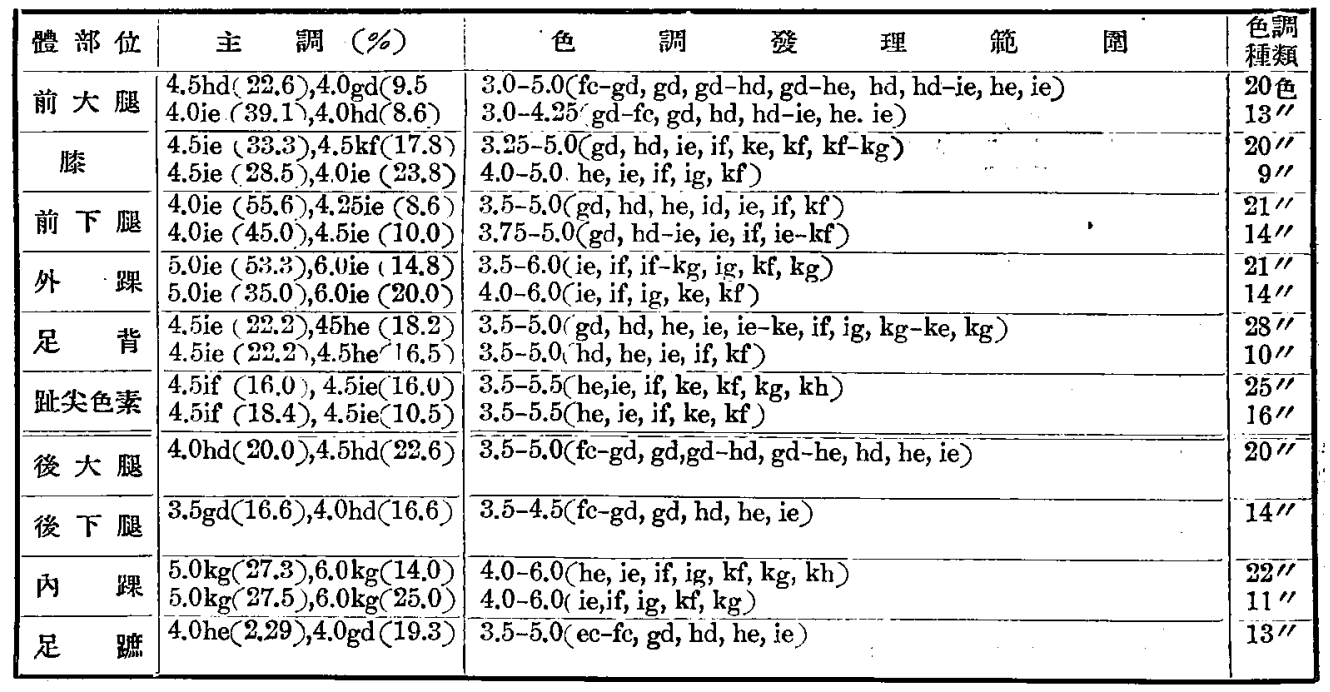

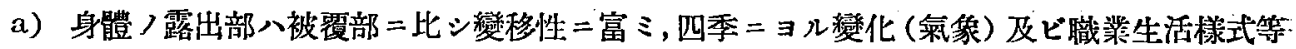


ニョル影響大ナリ。

b）身體前面（或八內側）八後面（或八外側）二比シ，白色度高ク䍃色度低シ（但シ下䁌） 場合八前後面二於ケル關係反對)。然シテ生殖器 (二次性生殖器 八黑色度著シ。

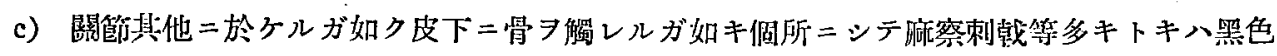
度及ビ基礎色ノ上景 $习$ 隶セリ。

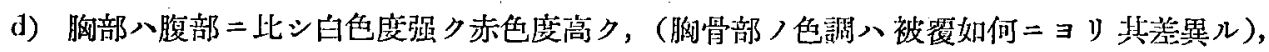
而シテ腹部中殊二褌ノ當ル遥及白線二相當セル部ノ皮膚色調八品色度强シ。

e）四肢つ遠側端或八下重部二於テ赤色应高マレリ。

f）日燒ノ影響蒙リ易キ部位（例 手背，後頸部）二於テ八㣴(褐)巴 墦セリ。

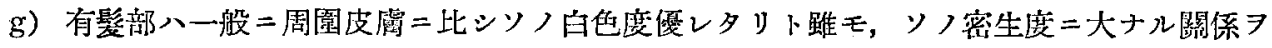

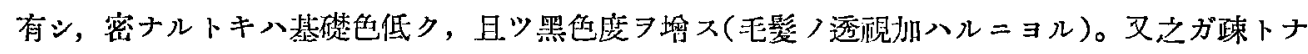
ルニ及ビ周图外皮 (皮碣) 色調二一致シ來ル。

4）先天的皺壁部八黑色優レ，皮下脂肪豐滿セル部位二於テハ白色度宫マル。

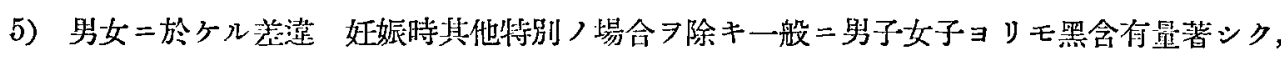
白及純色含有量ニツキテハ女子男子ヨ凌ギタリト雖モ環境其他ノ條件ニョリテ必ズシモ然ラズ (例 前膊, 膝等ノ黑色度女子男子二優レタルガ如シ)。

\section{文獻}

Bieniecki, Fall von hochgradigem Pigmentmangel der Haut, Wien. med. Zeitg. 3\$. Jilarg. 1893.

Caspary, Die Pathogenese der Pigmentierungen und Entfirbungen der Haut. Verh. des 10. internat. ned. Kongresses zu Berlin 4 Bd. 1892.

Halpern, Über das Verhalten des Pigenents in der Oberhaut des Menschen, Arch. f. Dermat, u. Syphilis 23 Bd. 1891.

Post, Über normale u, pathologische Pigmentierung der Oberbautgebilde, Anat. Anz, 8 Bd. 1893.

Schoemaker, Pign entation of the skin, J. Americ. Med. Assoc. Chicago Vol. 22.

Smith, Extensive pigmentation of the skin, British J. dermat. Vol. 1903.

Beddoe, Observations on the natural colour of the skin in certain oriental races, The Journ. of the Anthropol. Instit. of Great Britain and Ireliund Vol. 19, 1891.

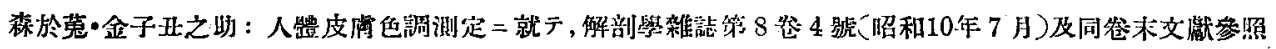

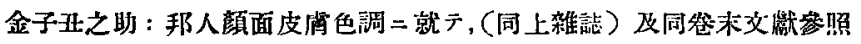

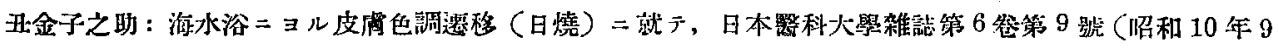

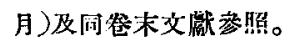

